\title{
Inflammatory IL-15 is required for optimal memory T cell responses
}

\author{
Martin J. Richer, ${ }^{1}$ Lecia L. Pewe, ' Lisa S. Hancox, ${ }^{1}$ Stacey M. Hartwig,, ${ }^{1}$ Steven M. Varga, ${ }^{1,2,3}$ and John T. Harty $1,2,3$ \\ 'Department of Microbiology, ${ }^{2}$ Department of Pathology, and ${ }^{3}$ Interdisciplinary Graduate Program in Immunology, University of lowa, lowa City, lowa, USA.
}

\begin{abstract}
Due to their ability to rapidly proliferate and produce effector cytokines, memory CD8+ $\mathrm{T}$ cells increase protection following reexposure to a pathogen. However, low inflammatory immunizations do not provide memory CD8 ${ }^{+} \mathrm{T}$ cells with a proliferation advantage over naive CD8 ${ }^{+} \mathrm{T}$ cells, suggesting that cell-extrinsic factors enhance memory CD8 ${ }^{+} \mathrm{T}$ cell proliferation in vivo. Herein, we demonstrate that inflammatory signals are critical for the rapid proliferation of memory CD $8^{+} \mathrm{T}$ cells following infection. Using murine models of viral infection and antigen exposure, we found that type I IFN-driven expression of IL-15 in response to viral infection prepares memory $\mathrm{CD8}^{+} \mathrm{T}$ cells for rapid division independently of antigen reexposure by transiently inducing cell-cycle progression via a pathway dependent on mTOR complex-1 (mTORC1). Moreover, exposure to IL-15 allowed more rapid division of memory $\mathrm{CD8}^{+} \mathrm{T}$ cells following antigen encounter and enhanced their protective capacity against viral infection. Together, these data reveal that inflammatory IL-15 promotes optimal responses by memory CD8+ T cells.
\end{abstract}

\section{Introduction}

Memory $\mathrm{CD}^{+} \mathrm{T}$ cells play a critical role in protection from pathogen reexposure. In addition to an increase in precursor frequency, memory $\mathrm{CD}^{+} \mathrm{T}$ cells possess various functional advantages that enhance their protective capacity compared with their naive counterparts. These include the capacity to rapidly produce effector cytokines and kill infected target cells (1-3). In addition, despite a similar lag time for cell-cycle entry in vivo (3), memory $\mathrm{CD}^{+} \mathrm{T}$ cells divide and accumulate more rapidly than naive $\mathrm{CD}^{+} \mathrm{T}$ cells (3-7). A recent report demonstrated that, in the absence of inflammatory stimuli, memory $\mathrm{CD}^{+} \mathrm{T}$ cells do not proliferate faster than naive cells, but instead exhibit a higher antigen threshold for entry into the cell cycle (8). Systemic inflammatory cytokines have previously been shown to exert a greater influence on the expansion of potential of memory $\mathrm{CD} 8^{+} \mathrm{T}$ cells than naive $\mathrm{CD} 8^{+} \mathrm{T}$ cells (9). Together, these studies strongly suggest that inflammatory cues play an important role in regulating the rapid division of memory $\mathrm{CD} 8^{+} \mathrm{T}$ cells observed in vivo over the course of infection.

Recent studies demonstrate that inflammatory cytokines have profound effects on the biology of memory $\mathrm{CD}^{+} \mathrm{T}$ cells independently of antigen reexposure. These include the capacity to rapidly traffic to inflamed tissues independently of antigen recognition as well as a transient increase in the antigen sensitivity of memory $\mathrm{CD}^{+} \mathrm{T}$ cells (10-12). In addition, several lines of evidence suggest that inflammatory cytokines can affect the cell-cycle properties of memory $\mathrm{CD}^{+} \mathrm{T}$ cells in a bystander manner (13-16). In particular, a recent study demonstrated that in vitro treatment with IL-12 and IL-18 leads to the proliferation of memory CD8 ${ }^{+} \mathrm{T}$ cells in an IL-2-dependent manner and suggested that this may be important in protection from reinfection (15). Additionally, Sprent and colleagues showed that infection with viruses (16) or injection of

Conflict of interest: The authors have declared that no conflict of interest exists. Submitted: January 30, 2015; Accepted: June 18, 2015.

Reference information: J Clin Invest. 2015;125(9):3477-3490. doi:10.1172/JCI81261. adjuvants (17) can stimulate proliferation of memory-phenotype $\mathrm{CD}^{+} \mathrm{T}$ cells generated through homeostatic proliferation in lymphopenic adult thymectomized mice. However, it remains unknown whether or how virus infection stimulates bystander proliferation of bona fide antigen-specific memory $\mathrm{CD}^{+} \mathrm{T}$ cells in normal mice. More importantly, it is currently unclear whether such proliferation is simply a bystander effect or plays an important role in the protective capacity of memory cells for rapid division following antigen encounter.

IL-15 is critical for the maintenance of memory CD8 $8^{+} \mathrm{T}$ cells, which it achieves by controlling basal proliferation (18-20), and it may be involved in the bystander proliferation of memory-like $\mathrm{CD}^{+} \mathrm{T}$ cells (17), although this role has not been established for bona fide antigen-specific memory $\mathrm{CD}^{+} \mathrm{T}$ cells. Intriguingly, recent data have demonstrated that IL-15 produced following inflammatory challenges plays an important role in the trafficking of memory $\mathrm{CD}^{+} \mathrm{T}$ cells (11). This suggests a novel role for inflammatory IL-15 (this term will be used herein to denote IL-15 induced following infection and differentiate it from basal levels of IL-15, which play a role in homeostatic maintenance of memory $\mathrm{CD}^{+}$ $\mathrm{T}$ cells; refs. 20,21) in optimizing memory $\mathrm{CD} 8^{+} \mathrm{T}$ cell responses over the course of secondary infection. As steady-state levels of IL-15 can regulate the basal proliferation of memory CD8 ${ }^{+} \mathrm{T}$ cells, we asked whether the induction of this cytokine following viral infection regulates the rapid proliferative capacity of memory $\mathrm{CD}^{+} \mathrm{T}$ cells independently of antigen reencounter.

\section{Results}

Exposure to virus-induced inflammation induces the cell-cycle entry of memory $C D 8^{+} T$ cells. The milieu induced by virus infection may consist of multiple pro- and antiinflammatory cytokines (22). We used an unbiased method (microarray) to address the impact of virus-induced bystander inflammation on bona fide antigenspecific memory CD8 ${ }^{+} \mathrm{T}$ cells. To this end, naive P14 cells (Thy1.1, $\mathrm{T}$ cell receptor $\mathrm{Tg} \mathrm{CD} 8^{+} \mathrm{T}$ cells specific for $\mathrm{gp}_{33-41}$ of lymphocytic cho- 
A

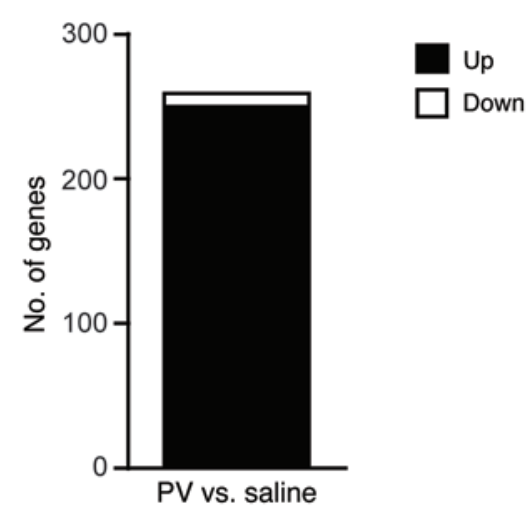

$\mathbf{B}$

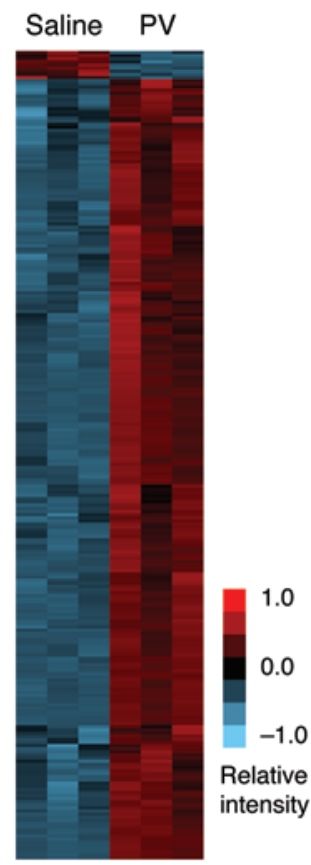

C

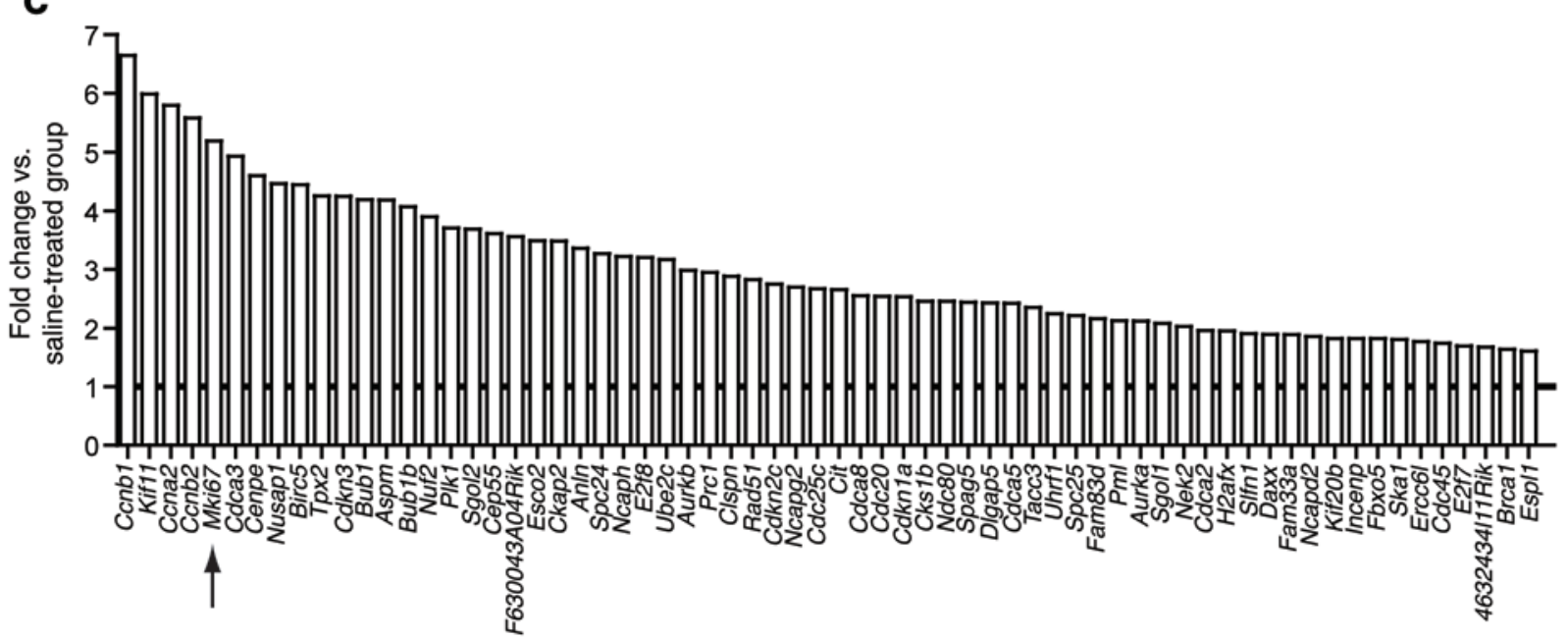

Figure 1. Viral infection induces the expression of cell-cycle genes by memory CD8 ${ }^{+} \mathbf{T}$ cells. (A) Number of genes differentially expressed in memory P14 cells on day 4 following PV infection compared with mock infection. (B) Heat map of differentially expressed genes. Each vertical lane represents an independent RNA pool. Color scale represents relative intensity of expression for each individual gene. (C) Expression levels of the 67 genes identified as belonging to the cell-cycle GO term by DAVID analysis in memory P14 cells exposed to virus-driven inflammation compared with saline-treated groups. Arrow indicates gene that encodes the Ki-67 protein. Data are from 3 independent RNA pools per group collected from at least 2 mice per pool $\left(1 \times 10^{6}\right.$ purified memory P14 cells per pool).

riomeningitis virus [LCMV]) were transferred to naive C57BL/6 mice (Thy1.2) followed by infection with LCMV. Fifty or more days later, mice were either mock infected or infected with pichinde virus (PV) (an arenavirus related to LCMV that does not express the P14 antigen) to provide virus-driven inflammation in the absence of cognate antigen. Memory P14 cells from each group were sorted from the spleen on day 4 following infection, and genome-wide mRNA expression was analyzed by microarray. PV infection significantly $(P<0.01$ and fold-change $>1.5)$ altered the expression of a large number $(>250)$ of genes in memory $\mathrm{CD}^{+} \mathrm{T}$ cells, the majority of which were upregulated compared with memory $\mathrm{CD} 8^{+} \mathrm{T}$ cells from mock-infected mice (Figure 1, A and B). We found signatures reflecting specific cytokine-response pathways, such as type
I IFN (data not shown). However, the most striking finding after Database for Annotation, Visualization and Integrated Discovery (DAVID) analysis of this gene set $(23,24)$ was the extensive upregulation of genes involved in the cell cycle (Table 1 and Figure 1C). In order to determine whether upregulation of these genes by virusdriven inflammation affects the cell-cycle properties of memory $\mathrm{CD}^{+} \mathrm{T}$ cells, memory P14 cells were enriched, labeled with CellTrace Violet (CTV), and adoptively transferred to naive C57BL/6 recipients. Recipient mice were mock infected with saline, infected with LCMV-Armstrong (LCMV-ARM) to provide both inflammation and cognate antigen, or infected with PV to provide virus-driven inflammation in the absence of cognate antigen. As expected, on day 4 after infection with LCMV-ARM, memory P14 cells had 
Table 1. DAVID analysis of differentially expressed genes in memory P14 $\mathrm{T}$ cells following mock infection or infection with PV

$\begin{array}{lcc}\text { GO TERM (top 5) } & \text { No. of genes } & \boldsymbol{P} \text { value } \\ \text { Cell cycle } & 67 & 5.60 \times 10^{-42} \\ \text { Cell-cycle process } & 56 & 1.30 \times 10^{-40} \\ \text { M phase } & 49 & 2.50 \times 10^{-39} \\ \text { M phase of the mitotic cell cycle } & 42 & 1.30 \times 10^{-37} \\ \text { Cell-cycle phase } & 50 & 2.00 \times 10^{-37}\end{array}$

undergone 8 or more rounds of division and all cells had high expression of Ki-67 (a marker that identifies cells that have entered any of the active phase of the cell cycle) (ref. 25, Figure 2A, and Supplemental Figure 1, A and B; supplemental material available online with this article; doi:10.1172/JCI81261DS1), leading to a significant $(P<0.001)$ increase in the number of P14 cells recovered from the spleen of infected mice (Figure 2B).

The mock-infection group exhibited a small percentage of memory P14 cells undergoing 1 or 2 divisions, representing the steady-state homeostatic proliferation of memory $\mathrm{CD}^{+} \mathrm{T}$ cells (Figure 2A) and significantly $(P<0.001)$ lower expression of Ki-67 on a per-cell basis compared with LCMV-infected mice (Supplemental Figure 1, A and B). Exposure to inflammation driven by PV induced a low level of bystander proliferation, as previously described (less than 4 divisions) $(13,14,16)$, but did not lead to any increase in the numbers of memory P14 cells recovered (Figure 2B) and was also coupled with lower expression of Ki-67 on a per-cell basis compared with P14 cells in LCMV-infected mice (Figure 2A and Supplemental Figure 1, A and B). This suggests that bystander infection induces memory $\mathrm{CD} 8^{+} \mathrm{T}$ cell proliferation that may be more similar to homeostatic proliferation than antigen-driven proliferation, as it is coupled with lower expression of Ki-67 and does not result in expansion in numbers of the population.

Although the extent of bystander division of memory P14 after PV infection was modest ( $<4$ division), the vast majority of memory P14 cells became positive for Ki-67 staining (Figure 2, C and D). This observation validated our microarray findings demonstrating upregulation of the $M k i 67$ gene following exposure to virus-driven inflammation ( $>5$-fold upregulation, Figure $1 C)$. In addition, this observation was not limited to P14 cells or to PV infection, as the majority of memory OT-I Tg CD8 ${ }^{+} \mathrm{T}$ cells (specific for $\mathrm{OVA}_{257-264}$ and generated by listeria-ova infection) also became positive for Ki-67 on day 4 following LCMV-ARM infection (Figure 2, E and F). Similarly, a large proportion of endogenous memory CD $8^{+} \mathrm{T}$ cells specific for LCMV-gp33 or -gp276 (as identified by MHC-tetramer staining) expressed Ki-67 on day 4 following bystander infection with PV (Figure 2, G-J). These data demonstrate that exposure to viral-driven inflammation induces the cell-cycle entry of the majority of memory $\mathrm{CD} 8^{+} \mathrm{T}$ cells regardless of their antigenic specificity.

Entry into the active phase of the cell cycle by memory $\mathrm{CD} 8^{+}$ T cells occurred rapidly, as we observed a significant $(P<0.001)$ increase in Ki- $67^{+}$memory P14 cells on day 2 following infection in both the spleen and inguinal lymph nodes (Figure 3). The majority of memory $\mathrm{CD} 8^{+} \mathrm{T}$ cells expressed Ki- 67 within 3 days following exposure to viral inflammation in the absence of antigenic stimulation (Figure 3). However, the effects of bystander inflammation on memory $\mathrm{CD} 8^{+} \mathrm{T}$ cells were transient, as the percentage of Ki- $67^{+}$cells decreased by day 7 and returned to below baseline by day 15 after infection (Supplemental Figure 2). These data demonstrate that exposure to virus-induced inflammation rapidly but transiently induces cell-cycle entry (as measured by Ki-67 expression) of memory $\mathrm{CD}^{+} \mathrm{T}$ cells. This suggests that exposure to inflammatory cytokines may provide a short window during which memory $\mathrm{CD} 8^{+} \mathrm{T}$ cells are primed for rapid division if they reencounter cognate antigen.

Virus-driven inflammation preferentially induces the cell-cycle entry of memory $C D 8^{+} T$ cells. To address whether the capacity of inflammatory cytokines to induce cell-cycle entry by $\mathrm{CD} 8^{+} \mathrm{T}$ cells was limited to the memory subset, memory and naive $\mathrm{P} 14 \mathrm{Tg} \mathrm{CD} 8^{+}$ $\mathrm{T}$ cells were enriched and adoptively transferred to naive $\mathrm{C} 57 \mathrm{BL} / 6$ recipients. Mice were then either mock-infected or infected with PV to provide inflammatory cytokines in the absence of antigen stimulation. While the majority $(86.6 \% \pm 0.7 \%)$ of memory P14 cells became Ki- $67^{+}$, only a small fraction $(12.1 \% \pm 1.8 \%)$ of naive P14 cells became Ki- $67^{+}$on day 4 following PV infection (Figure 4). This demonstrates that the capacity of viral-driven inflammation to drive $\mathrm{CD} 8^{+} \mathrm{T}$ cell entry into the cell cycle occurs preferentially within the memory subset.

Type I IFN-driven IL-15 induces cell-cycle entry of memory $C D 8^{+}$ $T$ cells independently of antigenic reencounter. In order to mechanistically determine how bystander viral infection regulates the cell-cycle entry by memory $\mathrm{CD} 8^{+} \mathrm{T}$ cells, we next asked whether specific inflammatory cytokines were directly involved in this phenomenon. We observed that both PV and LCMV-ARM (Figure 2) infection led to the cell-cycle entry (as measured by Ki-67 expression) of the majority of memory $\mathrm{CD} 8^{+} \mathrm{T}$ cells independently of antigen reexposure. These related arenaviruses both drive a strong inflammatory response that is dominated by the production of type I IFNs (26). Additionally, previous studies have linked type I IFNs to the proliferation of "memory-like" $\mathrm{CD} 8^{+} \mathrm{T}$ cells (16). Therefore, we asked whether type I IFN signaling is involved in regulating cellcycle entry of bona fide antigen-specific memory $\mathrm{CD} 8^{+} \mathrm{T}$ cells. WT memory P14 cells were enriched from the spleens of donor mice and adoptively transferred to either WT mice or mice lacking the type I IFN receptor (Ifnar $\left.1^{-/}\right)$. Type I IFN receptor deficiency did not substantially alter the percentage of Ki- $67^{+}$memory $\mathrm{CD}^{+} \mathrm{T}$ cells at steady state (Figure 5, A and B). However, on day 4 following infection with $\mathrm{PV}$, we observed a significant $(P<0.001)$ reduction in the percentage of memory P14 cells that were induced to express Ki-67 in Ifnar1 ${ }^{-1}$ recipients compared with memory P14 cells in WT recipients (Figure 5, A and B). As cells from Ifnar1-deficient mice are unable to respond to type I IFNs, this suggests a role for type I IFN signaling in regulating the cell-cycle entry of memory CD $8^{+} \mathrm{T}$ cells following bystander viral infection.

The preceding experiments did not allow us to determine whether the regulation of the cell-cycle entry resulted from a direct effect of type I IFN signaling on memory $\mathrm{CD}^{+} \mathrm{T}$ cells or rather from other indirect effects of reduced type I IFN signaling on other cell types. To address this, WT mice with populations of congenically marked WT or Ifnar $1^{-/}$memory OT-I cells were infected with LCMV-ARM and Ki-67 expression was measured on day 4 follow- 
A
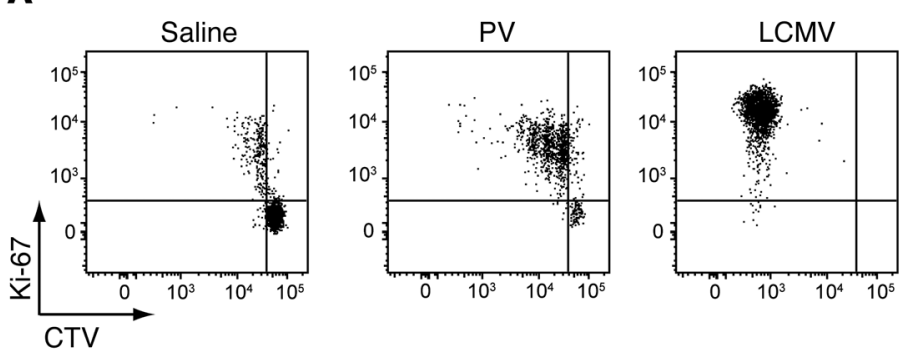

C
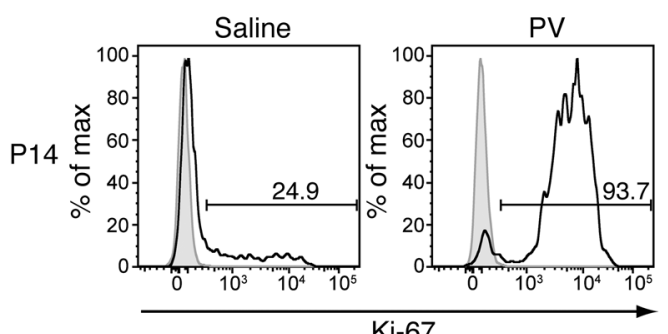

E

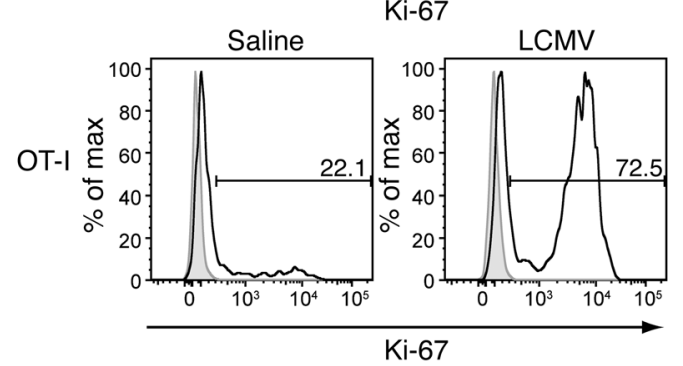

G

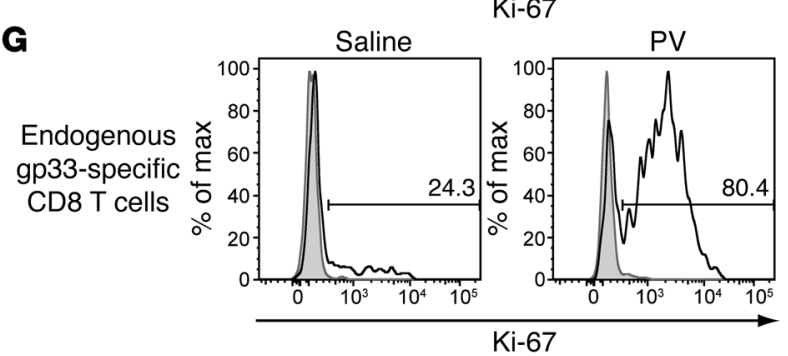

I

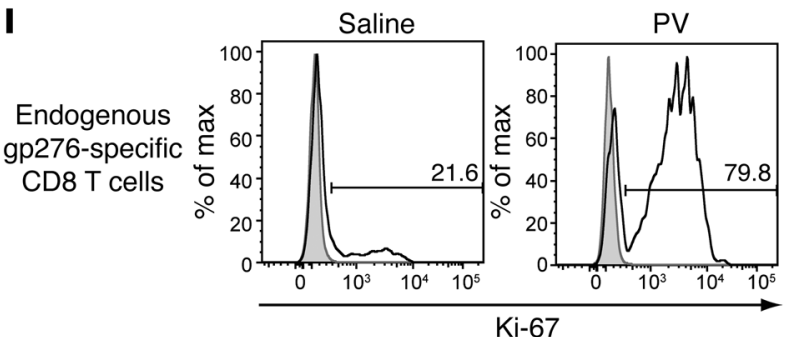

ing infection. As described above (Figure 2), LCMV-ARM infection resulted in a significant $(P<0.001)$ increase in the percentage of memory $\mathrm{CD}^{+} \mathrm{T}$ cells having entered the cell cycle (as marked by Ki-67 expression) (Figure 5, C and D). Strikingly, type I IFN receptor deficiency on memory $\mathrm{CD}^{+} \mathrm{T}$ cells did not reduce their capacity to enter the cell cycle following exposure to virus-driven inflammatory cytokines (Figure 5, C and D). Collectively, these data demonstrate that type I IFNs play an important but indirect role in regulating the cell-cycle entry of memory $\mathrm{CD}^{+} \mathrm{T}$ cells.

Next, we asked which factors were regulated by type I IFNs to control the antigen-independent cell-cycle entry of memory $\mathrm{CD}^{+} \mathrm{T}$ cells. Type I IFNs regulate the expression of several proteins including IL-15 (27), a cytokine that has been suggested to be
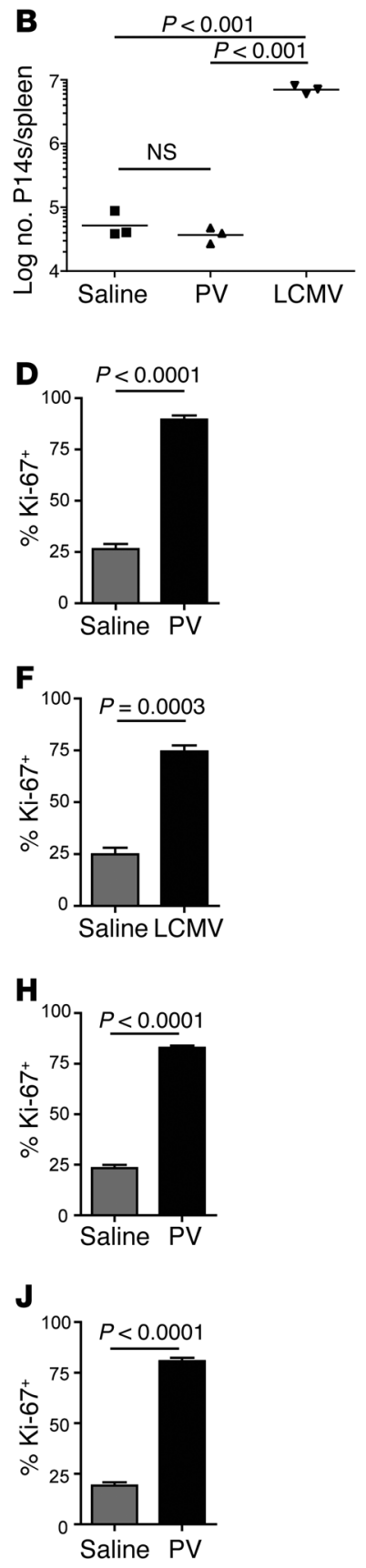

Figure 2. Viral infection induces cell-cycle entry of the majority of memory $\mathrm{CDB}^{+} \mathrm{T}$ cells independently of antigen reexposure. (A) Representative plots of cellular division and Ki-67 expression of adoptively transferred CTV-labeled memory P14 cells on day 4 following indicated treatment. (B) Total numbers of memory P14 cells recovered from the spleen on day 4 following the indicated treatment. (C) Representative plots of $\mathrm{Ki}-67$ expression by memory $\mathrm{P} 14$ cells on day 4 following indicated treatment. Shaded histograms represent isotype controls. (D) Cumulative data (mean \pm SEM) of $\mathrm{Ki}-67$ expression by memory $\mathrm{P} 14$ cells on day 4 following indicated treatment. (E and F) Same experimental design shown in $\mathbf{C}$ and $\mathbf{D}$ for memory OT-I on day 4 following LCMV infection. (G and $\mathbf{H}$ ) Same experimental design shown in $\mathbf{C}$ and $\mathbf{D}$ for endogenous gp33-specific memory $\mathrm{CD}^{+} \mathrm{T}$ cells as identified by tetramer staining. (I and J) Same experimental design shown in $\mathbf{C}$ and $\mathbf{D}$ for endogenous gp276specific memory $\mathrm{CD}^{+} \mathrm{T}$ cells as identified by tetramer staining. Data are from at least 3 mice per group and are representative of at least 2 independent experiments. Data in B were analyzed by 1-way ANOVA with Tukey's post-test of multiple comparisons, and data in $\mathbf{D}, \mathbf{F}, \mathbf{H}$, and $\mathbf{J}$ were analyzed by 2-tailed, unpaired Student's $t$ test.

involved in the antigen-independent regulation of memory CD $8^{+}$ $T$ cell function, such as trafficking to inflamed tissues (11) and the proliferation of "memory-like" $\mathrm{CD} 8^{+} \mathrm{T}$ cells (17). Therefore, we determined whether arenavirus infection induces IL-15 production in a type I IFN-dependent manner. Both WT and Ifnar-/ mice expressed similarly low but detectable basal amounts of IL-15 in the spleen prior to infection (Figure 5E). PV infection induced a significant $(P<0.001)$ increase in IL-15 expression in the spleen on day 2 after infection, and this was associated with a significant $(P=0.0002)$ increase in Il15 mRNA expression, suggesting that the increased IL-15 protein resulted from changes in transcription (Supplemental Figure 3A). This was, at least partially, regulated by type I IFN signaling, as Ifnar1 ${ }^{--}$mice expressed significantly 
A PV
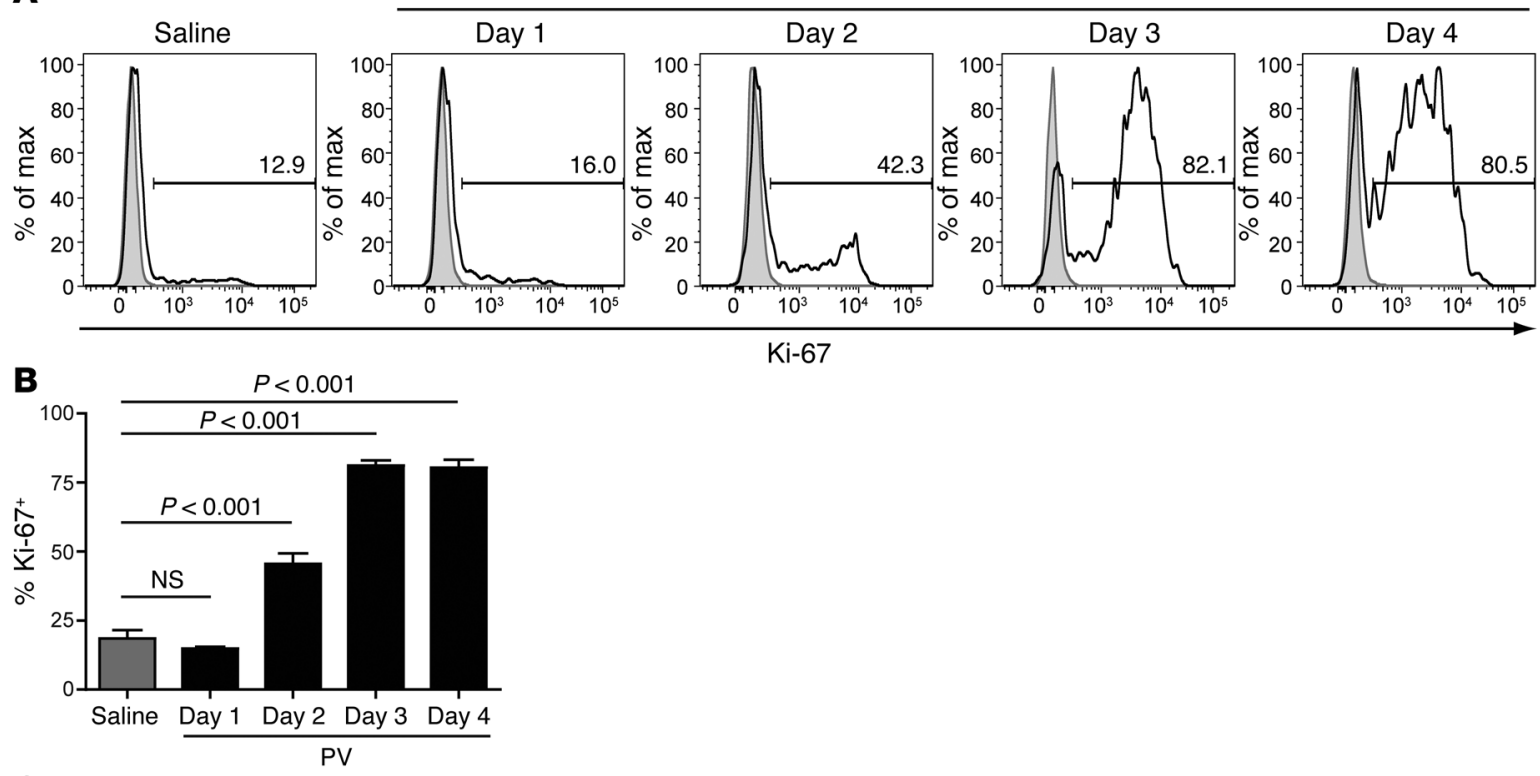

C

PV
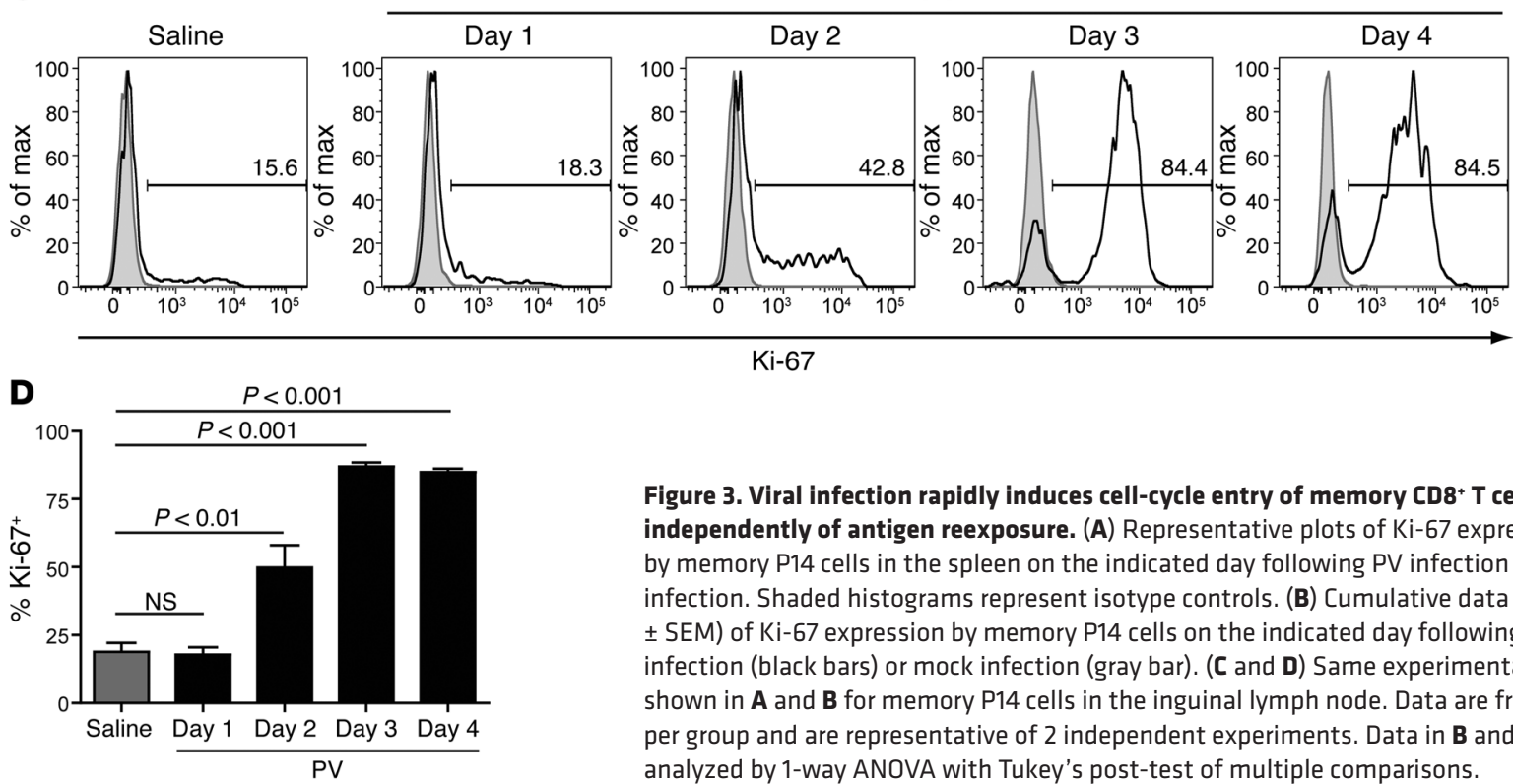

Figure 3. Viral infection rapidly induces cell-cycle entry of memory CD8+ $T$ cells independently of antigen reexposure. (A) Representative plots of Ki-67 expression by memory P14 cells in the spleen on the indicated day following PV infection or mock infection. Shaded histograms represent isotype controls. (B) Cumulative data (mean \pm SEM) of Ki-67 expression by memory P14 cells on the indicated day following PV infection (black bars) or mock infection (gray bar). (C and $\mathbf{D})$ Same experimental design shown in $\mathbf{A}$ and $\mathbf{B}$ for memory P14 cells in the inguinal lymph node. Data are from $\mathbf{3}$ mice per group and are representative of $\mathbf{2}$ independent experiments. Data in $\mathbf{B}$ and $\mathbf{D}$ were analyzed by 1-way ANOVA with Tukey's post-test of multiple comparisons.

$(P<0.001)$ reduced IL-15 levels following PV infection (Figure $5 \mathrm{E})$. This demonstrates that type I IFN induction following viral infection is a major regulator of IL-15 expression.

In order to directly examine a role for IL-15 in the regulation of the cell-cycle entry of bona fide antigen-specific memory $\mathrm{CD}^{+} \mathrm{T}$ cells, WT mice with a population of memory P14 cells were infected with PV and treated daily with either control IgG or a blocking antibody directed at CD122 (IL-2/IL15R $\beta$, a signaling component for both IL-2 and IL-15). While PV infection significantly $(P<0.001)$ increased the percentage of memory $\mathrm{CD} 8^{+} \mathrm{T}$ cells entering the cell cycle (as marked by Ki-67 expression) in control IgG-treated mice, this was completely abrogated in mice treated with anti-CD122 antibody (Figure 6, A and B), suggesting an important role for IL-2 or IL-15 signaling in regulating cell-cycle entry of memory $\mathrm{CD}^{+} \mathrm{T}$ cells over the course of infection. Importantly, a large proportion of the cell-cycle genes upregulated following PV infection (Figure 1 and Table 1) were induced downstream of CD122 signaling, as demonstrated by reduced expression of these genes following CD122 blockade (Supplemental Figure 3, B and C, and Supplemental Table 1). The relative contribution of IL-15 and IL-2 was addressed by adoptively transferring WT memory $\mathrm{P} 14 \mathrm{Tg} \mathrm{CD}^{+} \mathrm{T}$ cells into either WT or $\mathrm{Il15}$-/ hosts or with in vivo blockade using antibodies directed at IL-2. While induction of cell-cycle entry of WT memory CD8 ${ }^{+} \mathrm{T}$ cells by viral infection was completely abrogated in IL-15-deficient hosts (Figure 6, C and D), blockade of IL-2 had no effect (Supplemental Figure 4). Further, we addressed which cell population is responsible for the production of IL-15 following viral infection. Biologically active IL-15 is presented on the cell surface as a complex with the IL-15R $\alpha$ chain (CD215), usually on macrophage/monocytes or dendritic cells $(28,29)$. Therefore, we measured the induction of CD215 on antigen-presenting cell populations to determine which cell populations are responsible for the enhanced transpresenta- 
A
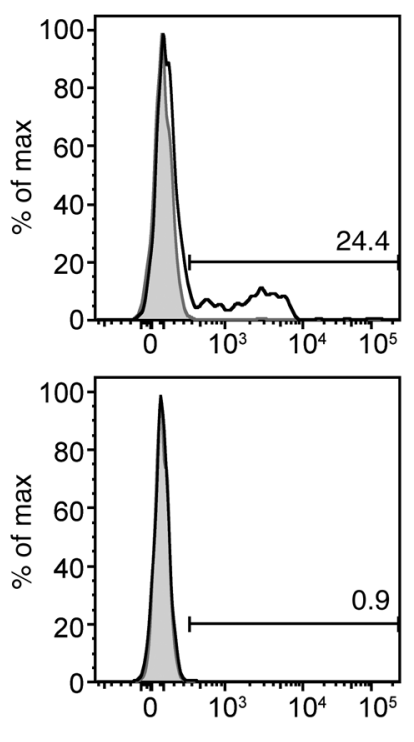

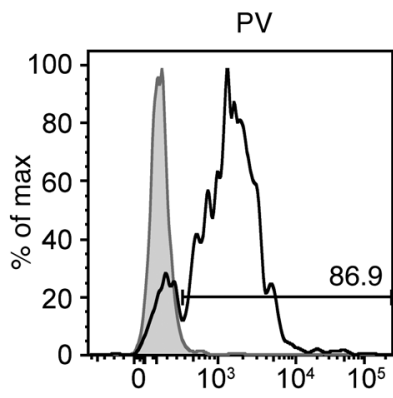

Memory
P14

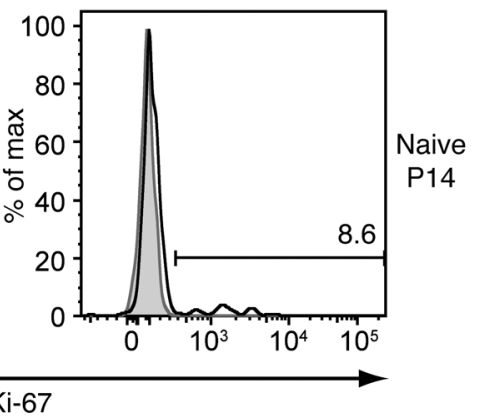

B

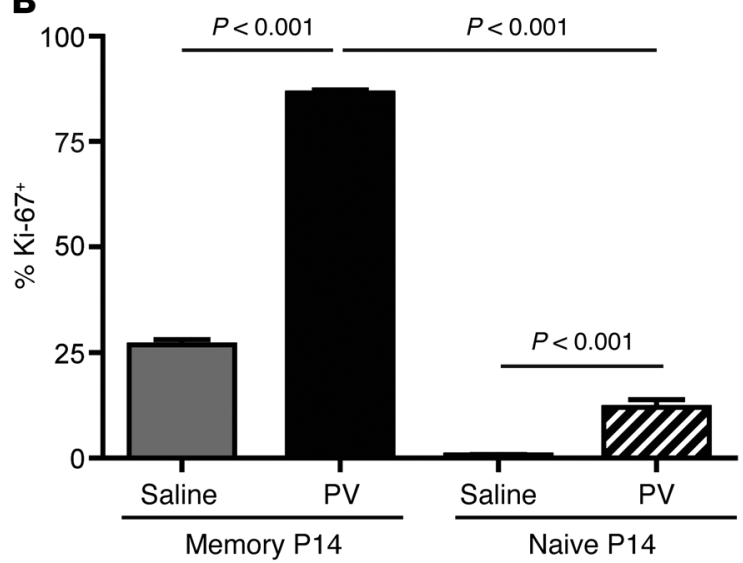

Figure 4. The capacity of virus-driven inflammation to induce cell-cycle entry is largely restricted to memory CD8 ${ }^{+}$T cells. (A) Representative plots of Ki-67 expression by adoptively transferred memory or naive P14 cells on day 4 following PV infection or mock infection. Shaded histograms represent isotype controls. (B) Cumulative data (mean \pm SEM) of Ki-67 expression in adoptively transferred memory or naive P14 cells on day 4 following PV infection or mock infection. Data are from at least 3 mice per group and are representative of 2 independent experiments. Data in B were analyzed by 1-way ANOVA with Tukey's post-test of multiple comparisons.

tion of IL-15. We observed a significant increase in IL-15R $\alpha$ on dendritic cells following PV infection, suggesting that, as previously described $(28,29)$, dendritic cells play an important role in the production of IL-15 (Supplemental Figure 5). We also observed a quite modest, but statistically significant increase in IL-15R $\alpha$ expression on macrophage/monocyte and B cells, suggesting that other cell types may make a minor contribution to IL-15 production following viral infection (Supplemental Figure 5). Taken together, these data demonstrate that induction of IL-15, but not IL-2, following viral infection allows memory cells to enter the cell cycle regardless of their antigenic specificity.

Inflammatory $I L-15$ induces cell-cycle entry of memory $C D 8^{+} T$ cells via a pathway dependent on the mTOR complex-1 pathway. We next wanted to determine the signaling pathway involved in inducing cell-cycle entry of memory $\mathrm{CD}^{+} \mathrm{T}$ cells following exposure to inflammatory IL-15. The metabolic checkpoint kinase mTOR has been well described as integrating various stimulatory cues and regulating multiple cell processes, including cell-cycle progression $(30,31)$. In addition, recent data have shown an essential role for the mTOR complex-1 (mTORC1) downstream of IL-15 in NK cell function (32). Therefore, we directly examined the role of mTOR in the induction of cell-cycle entry of memory CD8 ${ }^{+} \mathrm{T}$ cells following exposure to inflammatory IL-15. Mice with a population of memory P14 cells were infected with PV and treated daily with either saline or the mTORC1-specific inhibitor rapamycin (33). While PV infection significantly $(P<0.001)$ increased the percentage of memory $\mathrm{CD} 8^{+} \mathrm{T}$ cells entering the cell cycle (as marked by Ki-67 expression) in control-treated mice compared with mockinfected mice, this increase in Ki-67 was completely abrogated in mice treated with rapamycin (Figure 6, E and F). Importantly, rapamycin treatment did not reduce the antigen-independent enhancement of granzyme B in memory $\mathrm{CD}^{+} \mathrm{T}$ cells exposed to inflammation, in which granzyme B enhancement is dependent on direct type I IFN signaling (ref. 34 and Supplemental Figure 6). These data demonstrate that exposure to inflammatory IL-15 activates the mTORC1-signaling pathway to induce cell-cycle entry of memory $\mathrm{CD}^{+} \mathrm{T}$ cells and that this pathway is independent of the type I IFN-mediated effect on $\mathrm{CD}^{+} \mathrm{T}$ cell effector function.

The preceding experiments did not allow us to determine whether rapamycin had a direct effect on $\mathrm{CD}^{+} \mathrm{T}$ cells. Therefore, to address a direct link among IL-15 receptor signaling (largely STAT5 dependent), mTOR, and a relevant target of mTOR involved in cell-cycle progression, memory P14 cells were enriched and stimulated ex vivo with IL-15 alone or together with either a STAT5 inhibitor or rapamycin. We investigated activation of a welldescribed target of mTOR involved in cell-cycle progression, p70 S6 kinase $(35,36)$. Activation of p70 S6 kinase activity is regulated by several phosphorylation events, including phosphorylation of threonine 389 by mTORC1. Stimulation of memory P14 cells with IL-15 resulted in the phosphorylation of p70 S6 kinase (Figure 6G). Importantly, inhibition of either STAT5 signaling or mTORC1 activity (with rapamycin) completely abrogated phosphorylation of p70 S6 kinase. Taken together, these results demonstrate that IL-15 stimulation of memory $\mathrm{CD}^{+} \mathrm{T}$ cells leads to the activation of the mTOR pathway in a STAT5-dependent manner, leading to the phosphorylation of p70 S6 kinase. Therefore, these data provide a mechanistic link between exposure to inflammatory IL-15 and the regulation of the cell-cycling capacity of memory $\mathrm{CD} 8^{+} \mathrm{T}$ cells.

Exposure to $I L-15$ prepares mouse and human $C D 8^{+} T$ cells for rapid division. Our data demonstrated that exposure to IL-15 induced following infection allows bona fide antigen-specific memory $\mathrm{CD}^{+} \mathrm{T}$ cells to enter the cell cycle independently of 
A
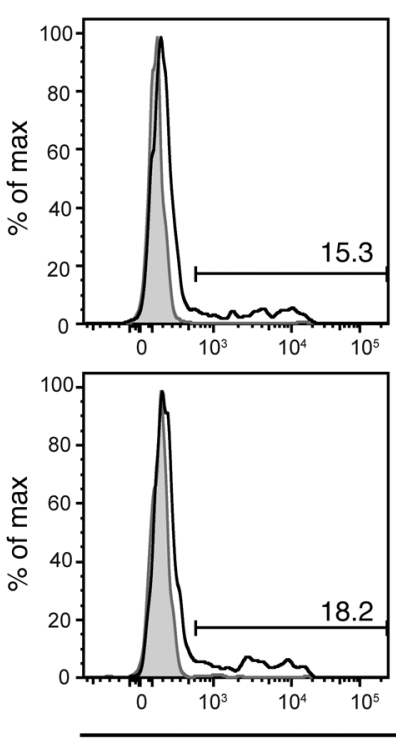

C
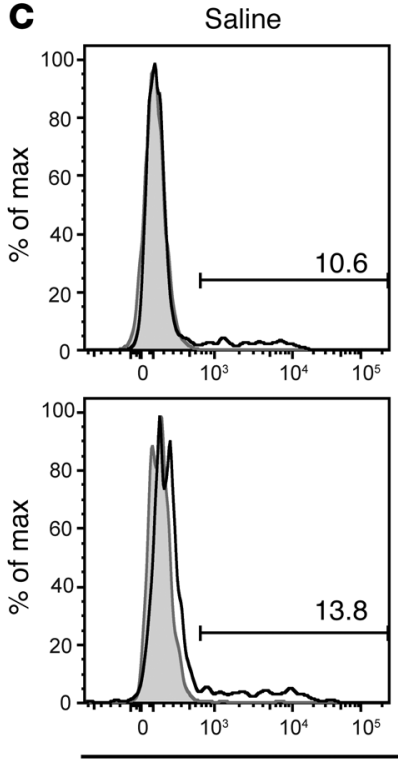
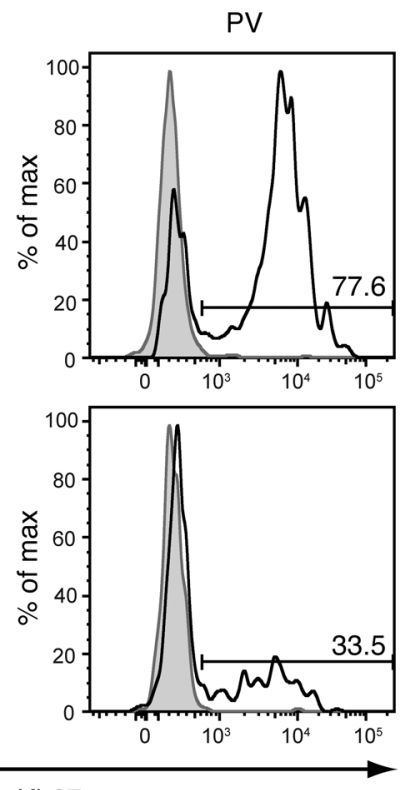

Ki-67
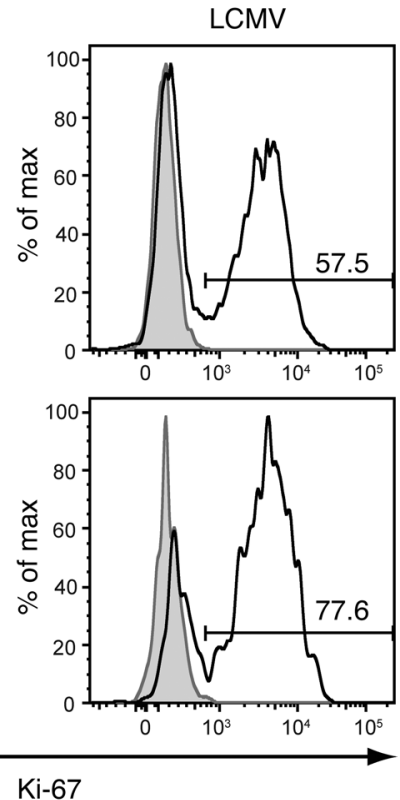

WT

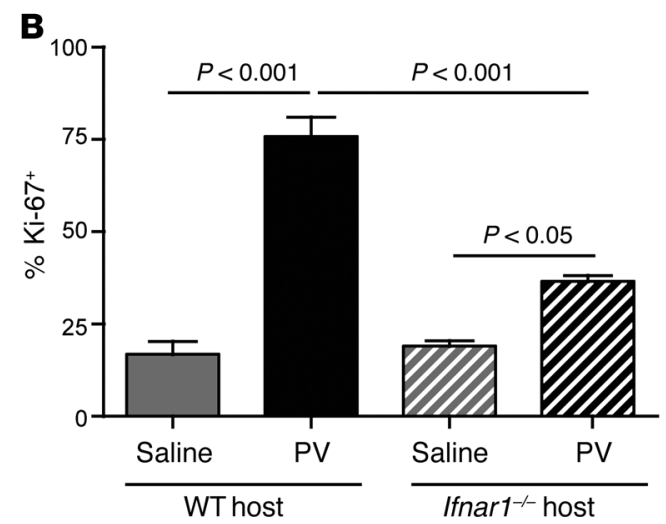

Ifnar1 $1^{-1-}$

WT

OT-I

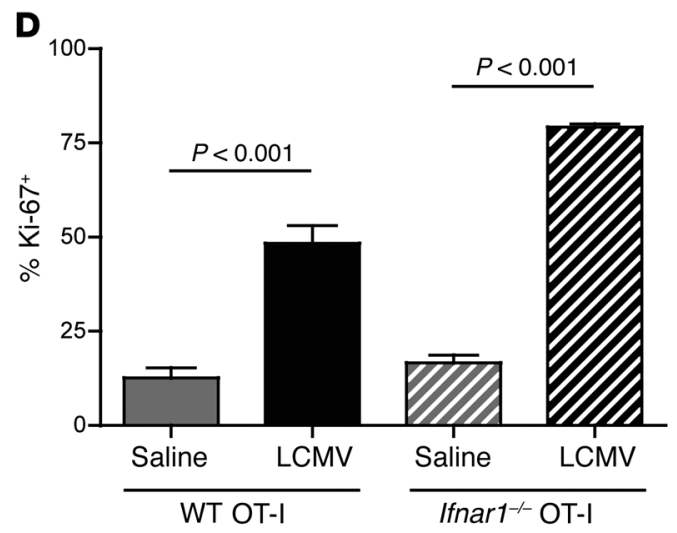

E

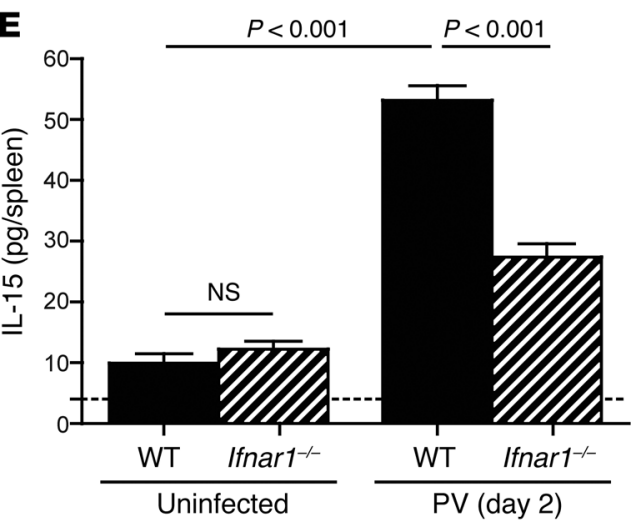

Figure 5. Type I IFN indirectly regulates cell-cycle entry of memory CD8+ T cells. (A) Representative plots of Ki-67 expression by memory P14 cells adoptively transferred to WT or Ifnar1-1- hosts on day 4 following PV infection or mock infection. Shaded histograms represent isotype controls. (B) Cumulative data (mean \pm SEM) of Ki-67 expression by memory P14 cells adoptively transferred to WT or Ifnar1 ${ }^{-1-}$ hosts on day 4 following PV infection or mock infection. (C) Representative plots of Ki-67 expression by WT or Ifnar1 ${ }^{-/-}$memory OT-I cells on day 4 following LCMV-ARM infection or mock infection. (D) Cumulative data (mean \pm SEM) of Ki-67 expression by WT or Ifnar1-/- memory OT-I cells on day 4 following LCMV-ARM infection or mock infection. (E) Cumulative data (mean \pm SEM) of IL-15 expression in the spleen of WT or Ifnar1-/- mice on day 2 following infection with PV or mock infection. Data are from 3 mice per group and are representative of 2 independent experiments. Data in B, D, and E were analyzed by 1-way ANOVA with Tukey's post-test of multiple comparisons.

antigen reexposure. We next determined whether this simply represents a bystander effect with no biological significance or whether it actually prepares memory $\mathrm{CD} 8^{+} \mathrm{T}$ cells for rapid division upon antigen encounter. Memory P14 cells were enriched and cultured with or without low doses of recombinant murine IL-15 for 4 days. This pretreatment was not sufficient to induce cell division (as measured by CTV dilution) in the majority of the cultured memory CD8 ${ }^{+} \mathrm{T}$ cells (Figure $7 \mathrm{~A}$ ). While the conditions used in the in vitro assay were more stringent than those in the in vivo (where low levels of proliferation did occur following bystander infection), they were still sufficient to induce Ki-67 expression (Supplemental Figure 7A). Cells were then washed to remove any remaining IL-15 and stimulated with cognate $\mathrm{GP}_{33-41}$ peptide. Strikingly, despite the stringent conditions employed, IL-15 pretreatment led to faster division of memory $\mathrm{CD}^{+} \mathrm{T}$ cells following peptide stimulation (Figure 7A and Supplemental Table 2). These data demonstrate that exposure of memory $\mathrm{CD}^{+} \mathrm{T}$ cells to IL-15 prepares the cells for faster division following cognate 
A

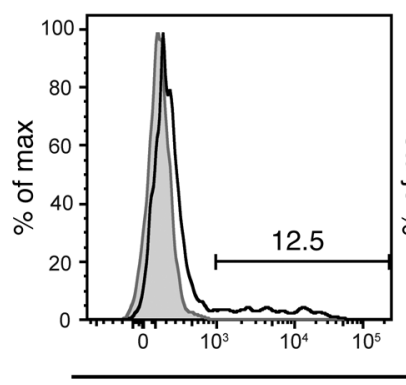

C Saline
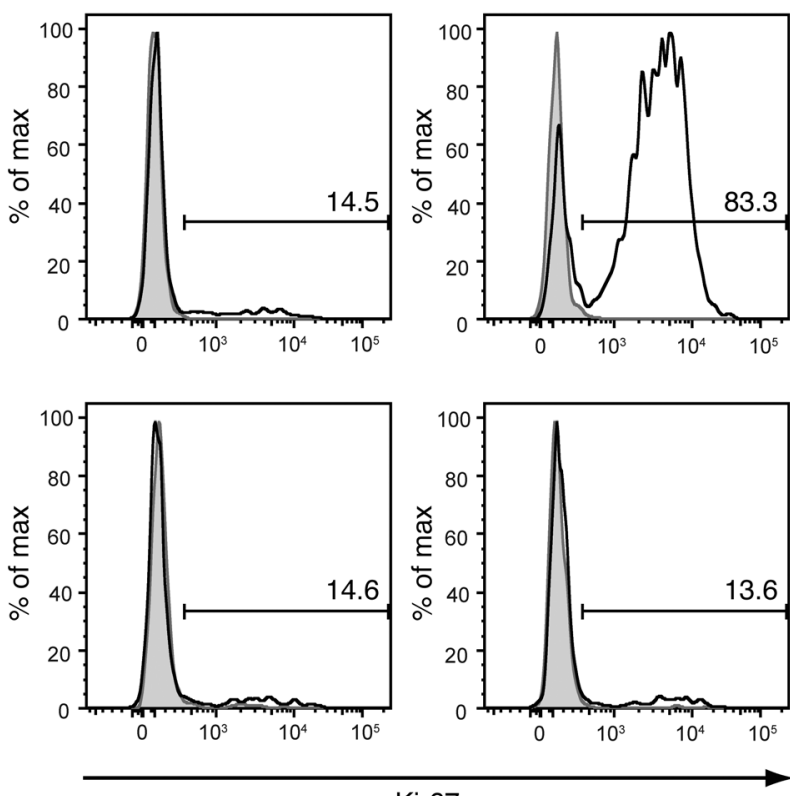

Ki-67

E

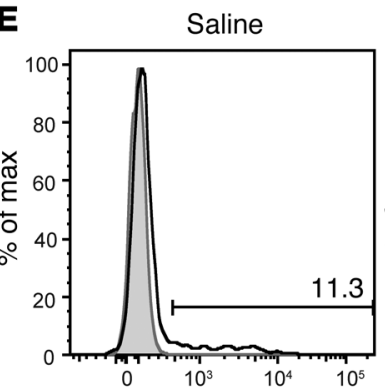

$P V+$ rat $\lg G$

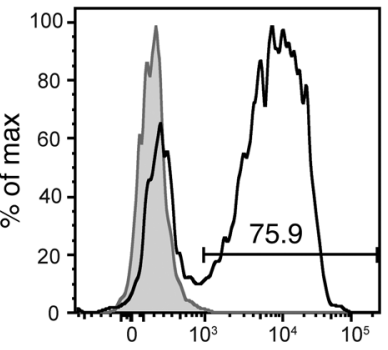

Ki-67

PV

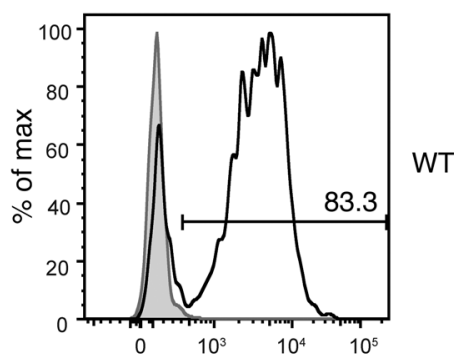

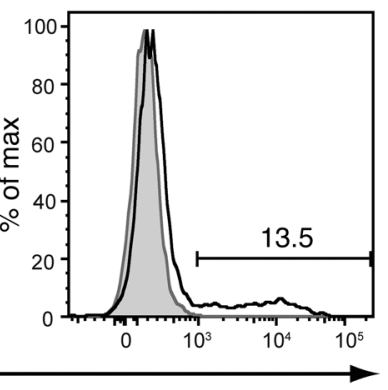

B

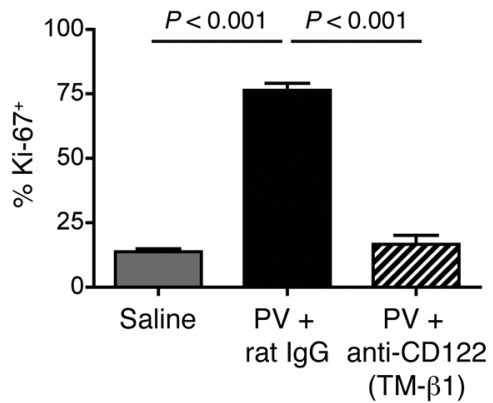

D
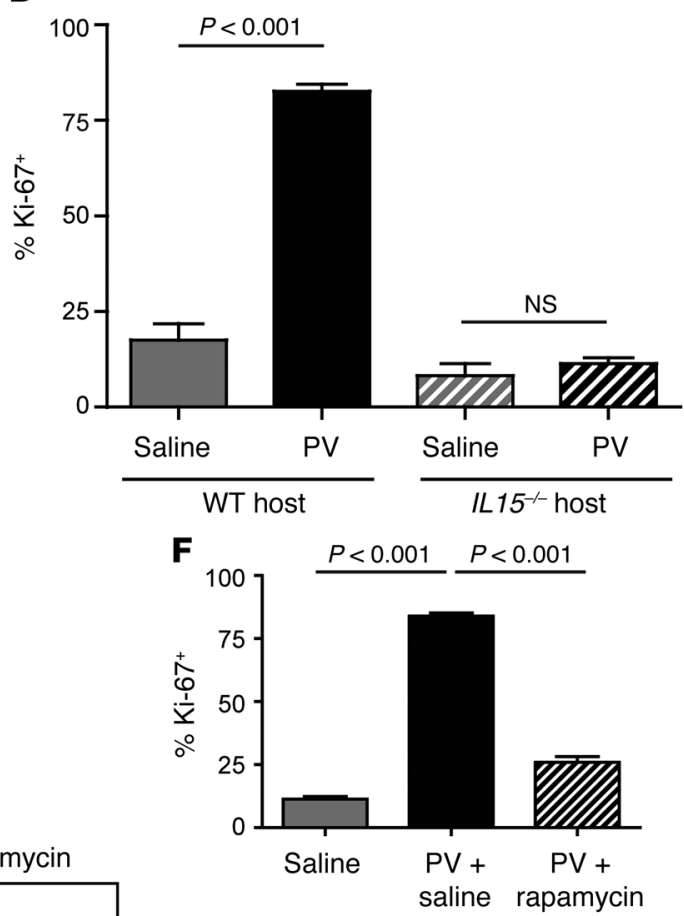

G

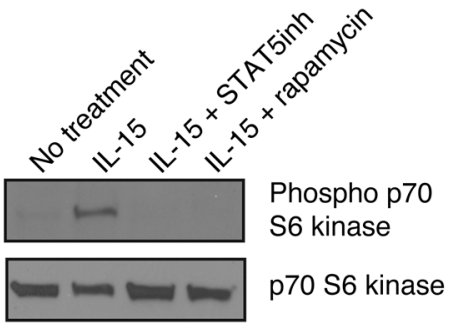

Figure 6. Inflammatory IL-15 induced following viral infection regulates cell-cycle entry of memory CD8 ${ }^{+} \mathrm{T}$ cells via a signaling pathway dependent on mTORC1. (A) Representative plots of Ki-67 expression by memory P14 cells on day 4 following mock infection or infection with PV followed by daily treatment with either rat IgC or anti-CD122 (clone TM- $\beta 1$ ) antibody as indicated. Shaded histograms represent isotype controls. (B) Cumulative data (mean \pm SEM) of Ki-67 expression by memory P14 cells on day 4 following indicated treatment. (C) Representative plots of Ki-67 expression by memory P14 cells adoptively transferred to WT or $/ 115^{-/-}$hosts on day 4 following PV infection or mock infection. Shaded histograms represent isotype controls. (D) Cumulative data (mean \pm SEM) of Ki-67 expression by memory P14 cells adoptively transferred to WT or $/ 115^{-/-}$hosts on day 4 following PV infection or mock infection. (E) Representative plots of Ki-67 expression by memory P14 cells on day 4 following mock infection or infection with PV with daily treatment with either saline or rapamycin as indicated. Shaded histograms represent isotype controls. (F) Cumulative data (mean \pm SEM) of Ki-67 expression by memory P14 cells on day 4 following indicated treatment. (C) Immunoblot analysis of cell lysates from enriched memory P14 cells for the indicated protein after indicated treatment. Data in $\mathbf{A}-\mathbf{F}$ are from 3 mice per group and are representative of at least 2 independent experiments. Data in $\mathbf{G}$ are from at least 15 pooled mice and are representative of 2 independent experiments. Data in B, D, and F were analyzed by 1-way ANOVA with Tukey's post-test of multiple comparisons. 
A

\section{P14 memory}

$\mathrm{CD}^{+} \mathrm{T}$ cells

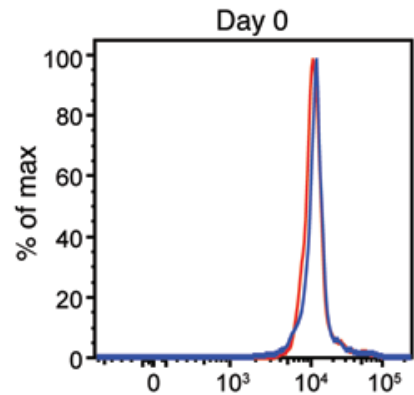

No pretreatment $\square \mathrm{IL}-15$ pretreatment

B Human $\mathrm{CD}^{+} \mathrm{CD} 3^{+}$ CD45RO ${ }^{+} \mathrm{T}$ cells
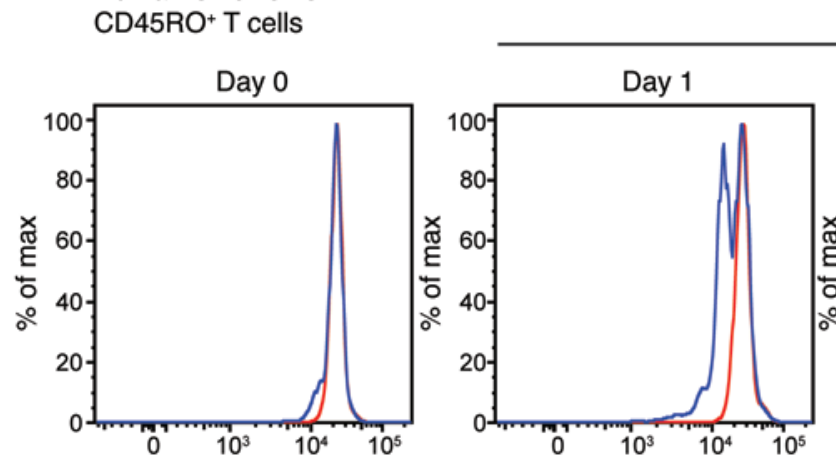
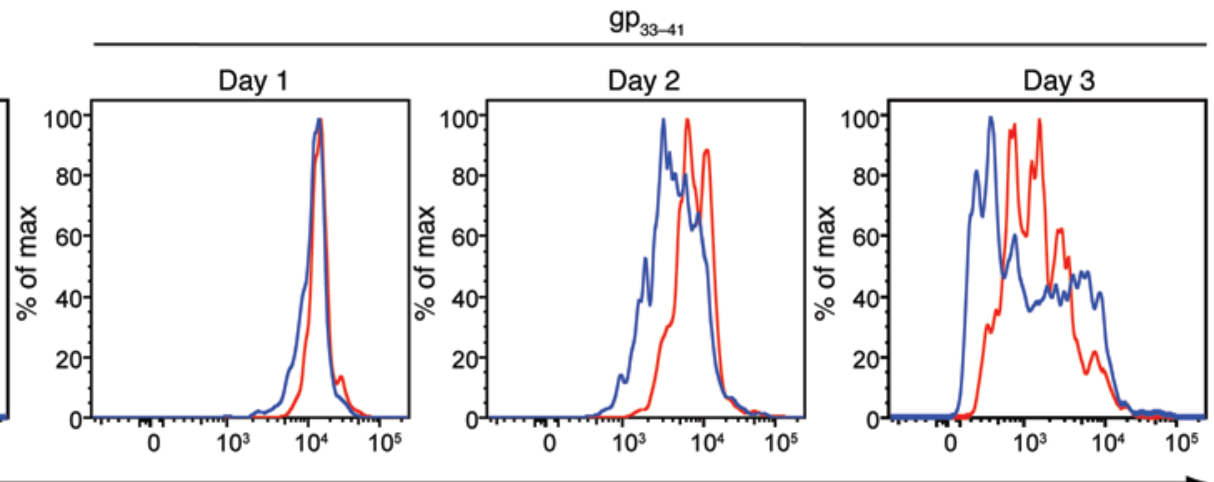

CTV
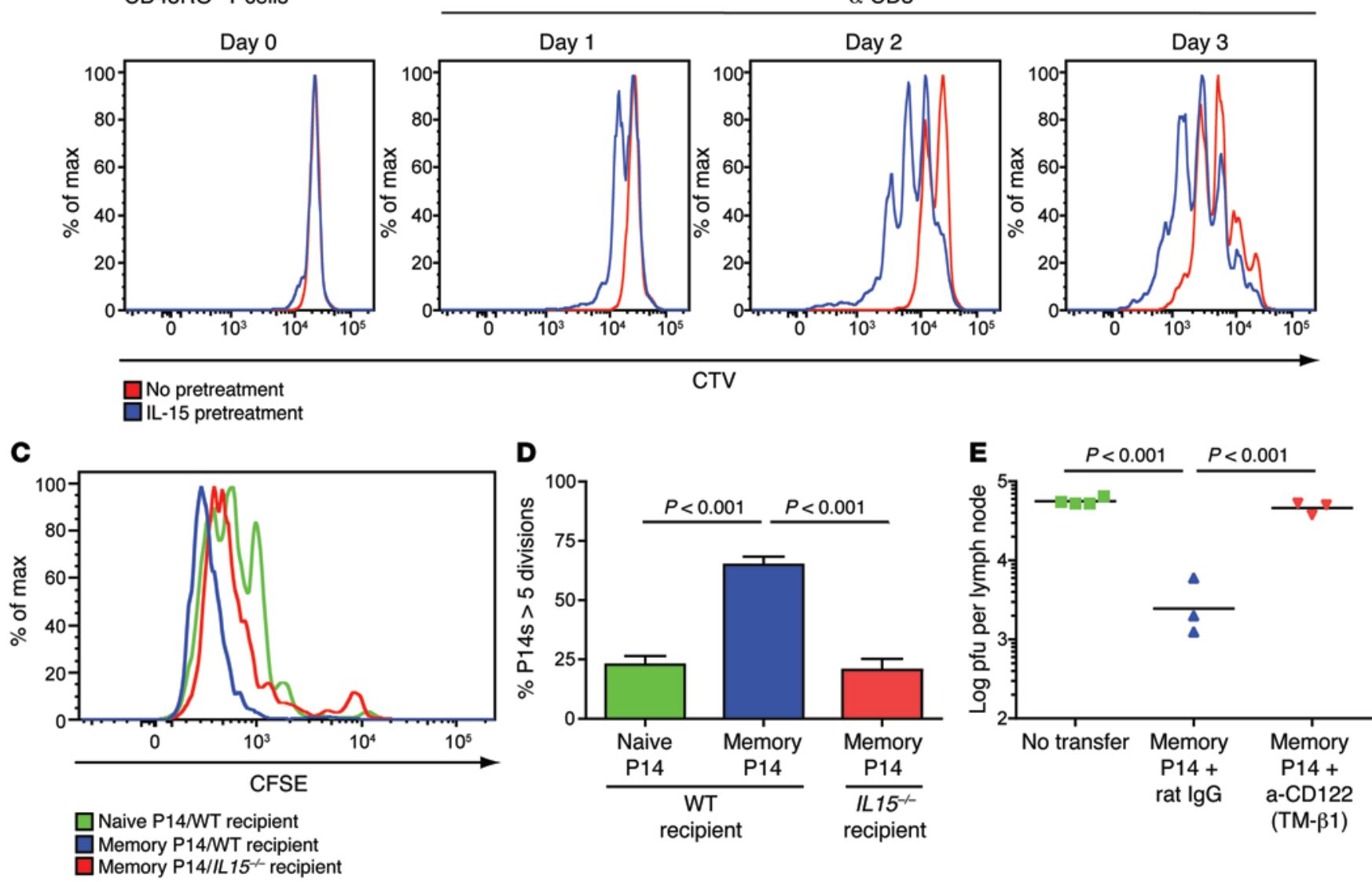

Figure 7. Exposure to IL-15 prepares memory CD8 ${ }^{+} \mathrm{T}$ cells for rapid division following $\mathrm{T}$ cell receptor triggering and is required for optimal proliferation and protective capacity. (A) Proliferation profiles (CTV dilution) of enriched memory P14 cells with (blue lines) or without (red lines) pretreatment with recombinant murine IL-15. Cells were then stimulated with cognate peptide $\left(\mathrm{gp}_{33-4)}\right)$ as indicated. (B) Same experimental design shown in $\mathbf{A}$ for antigenexperienced (CD8+ $\left.\mathrm{CD} 45 \mathrm{RO}^{+}\right)$human $\mathrm{CD} 8^{+} \mathrm{T}$ cells with (blue lines) or without (red lines) pretreatment with recombinant human IL-15 and stimulation with plate-bound anti-CD3. (C) Proliferation of naive P14 Tg CD8 ${ }^{+} \mathrm{T}$ cells transferred into WT hosts (green line) or memory P14 cells transferred into WT (blue line) or $1115^{-1-}$ hosts (red line) was measured by CFSE dilution on day 3 following LCMV-ARM infection. (D) Cumulative data (mean \pm SEM) of the percentage of naive or memory P14 cells transferred to WT or $1 / 15^{-1-}$ hosts (as indicated) having undergone greater than 5 divisions on day 3 following infection with LCMV-ARM. (E) Viral burden in the inguinal lymph node on day 3 following LCMV clone 13 infection of mice receiving either no adoptive transfer (green squares) or an adoptive transfer of memory P14 cells with daily treatment with either rat IgC (blue triangles) or anti-CD122 (clone TM- $\beta 1$ ) (red inverted triangles). Data in $\mathbf{A}$ are from more than 3 pooled mice and are representative of 2 independent experiments. Data in $\mathbf{B}$ are from 1 human donor and are representative of 2 experiments with different individual donors. Data in C-E are from at least 3 mice per group and are representative of at least 2 independent experiments. Data in $\mathbf{D}$ and $\mathbf{E}$ were analyzed by 1-way ANOVA with Tukey's post-test of multiple comparisons. 
peptide encounter. Similarly, we observed that pretreatment with low doses of recombinant human IL-15 did not induce cell division in the majority of antigen-experienced $\left(C D 45 \mathrm{RO}^{+}\right)$human $\mathrm{CD}^{+} \mathrm{T}$ cells while inducing the expression of Ki-67 (Figure 7B and Supplemental Figure 7B). Importantly, pretreatment with IL-15 also led to an increase in the proliferative capacity of these cells following stimulation with plate-bound anti-CD3 compared with the same population of cells that had not been pretreated (Figure 7B and Supplemental Table 2). Taken together, these data suggest that the capacity of memory $\mathrm{CD}^{+} \mathrm{T}$ cells to sense IL-15 following viral infection represents an important conserved regulatory mechanism that allows for the rapid proliferation of memory $\mathrm{CD}^{+} \mathrm{T}$ cells upon antigen encounter.

Inflammatory $I L-15$ regulates the proliferation and protective capacity of memory $C D 8^{+} T$ cells over the course of infection. Our data strongly suggest that IL-15 plays an important role in regulating the capacity of memory $\mathrm{CD}^{+} \mathrm{T}$ cells to proliferate more rapidly than naive cells over the course of an infection. In order to directly investigate the effect of IL-15 on the proliferation and protective capacity of memory $\mathrm{CD} 8^{+} \mathrm{T}$ cells, naive and memory P14 cells were enriched, CFSE labeled, and adoptively transferred to either WT or IL-15-deficient recipients. On day 3 following infection with LCMV-ARM (which expresses the cognate antigen for P14 cells and induces inflammatory cytokines), we observed that memory $\mathrm{CD}^{+} \mathrm{T}$ cells divided more rapidly than their naive counterparts (Figure 7C) in WT recipients. Strikingly, WT memory $\mathrm{CD}^{+} \mathrm{T}$ cells transferred into IL-15-deficient hosts exhibited a reduced proliferative rate compared with the same population of cells transferred into WT hosts. In fact, the percentage of memory $\mathrm{CD}^{+} \mathrm{T}$ cells having undergone greater than 5 divisions in IL-15-deficient hosts was similar to that observed in responding naive $\mathrm{CD}^{+} \mathrm{T}$ cells. In contrast, the percentage of memory $\mathrm{CD}^{+} \mathrm{T}$ cells undergoing greater than 5 divisions was significantly $(P<0.001)$ greater following transfer into WT hosts compared with IL-15-deficient hosts (Figure 7D). These data confirmed our in vitro results (Figure 7, A and B) and, together, demonstrate that the capacity of memory $\mathrm{CD}^{+} \mathrm{T}$ cells to respond to IL-15 is integral to the capacity of these cells to undergo rapid division over the course of an infection.

Since our data demonstrate an important role for IL-15 in the proliferative capacity of memory $\mathrm{CD}^{+} \mathrm{T}$ cells, we determined whether exposure to this cytokine is important for antiviral protection. A previous report from our laboratory demonstrated that control of LCMV clone 13 in the lymph node is dependent on the proliferation of memory CD8 ${ }^{+} \mathrm{T}$ cells (37). Importantly, protection is not dependent on $\mathrm{CD}^{+} \mathrm{T}$ cell trafficking and thus, this model avoids the complication of the role of IL-15 in trafficking to inflamed tissues $(11,37)$. Therefore, we asked whether the inability to sense IL-15 following viral infection would affect pathogen control in the lymph nodes. Enriched WT memory P14 cells were adoptively transferred to WT recipients. Mice were challenged with LCMV clone 13 and treated daily with either control rat IgG or anti-CD122. On day 3 following infection, we observed that, while transfer of memory $P 14$ cells significantly $(P<0.001)$ reduced viral burden in the lymph nodes, CD122 blockade completely abrogated the protective capacity of memory $\mathrm{CD} 8^{+} \mathrm{T}$ cells (Figure 7E). Furthermore, this treatment did not affect the capac- ity of inflammatory cytokines to enhance the antigen sensitivity of memory CD8 ${ }^{+} \mathrm{T}$ cells (Supplemental Figure 8, A and B), demonstrating that CD122 blockade does not affect the effector capacity of these cells. Importantly, CD122 blockade did not affect the capacity of naive mice (without adoptive transfer of memory CD8 ${ }^{+}$ $\mathrm{T}$ cells) to control viral infection, demonstrating that blockade did not affect the innate immune responses to infection (Supplemental Figure 8C). Collectively, our results indicate that the decreased protection is due to the reduction in the proliferative capacity of memory $\mathrm{CD}^{+} \mathrm{T}$ cells. Taken together, our data demonstrate what we believe is a novel role for inflammatory IL-15 induced following viral infection. Type I IFN-dependent induction of IL-15 allows activation of the mTOR pathway, causing memory cells to enter the cell cycle regardless of their antigenic specificity. This represents more than a bystander effect, as it primes memory $\mathrm{CD}^{+} \mathrm{T}$ cells for faster cell division after encountering their cognate antigen. This, in turn, yields an increase in the protective capacity of memory $\mathrm{CD}^{+} \mathrm{T}$ cells.

\section{Discussion}

Memory $\mathrm{CD}^{+} \mathrm{T}$ cells mediate increased protection from reinfection due to having several functional advantages over naive $\mathrm{CD}^{+} \mathrm{T}$ cells. Among these advantages is a well-described capacity for rapid proliferation of memory $\mathrm{CD} 8^{+} \mathrm{T}$ cells compared with their naive counterparts (3-7). Of note, proliferation of memoryphenotype $\mathrm{CD} 8^{+} \mathrm{T}$ cells generated in lymphopenic hosts has been observed after virus infection; however, these early studies did not distinguish between the responding virus-specific $\mathrm{CD}^{+} \mathrm{T}$ cells and preexisting memory-phenotype $\mathrm{CD}^{+} \mathrm{T}$ cells (16). Further studies showed that injection of adjuvants could stimulate proliferation of lymphopenia-driven memory-phenotype CD8 ${ }^{+} \mathrm{T}$ cells through type I IFN- and IL-15-dependent processes (17). However, it remained unknown whether bona fide memory $\mathrm{CD}^{+} \mathrm{T}$ cells generated in lympho-replete hosts undergo similar bystander proliferation and, more importantly, whether this bystander proliferation influences the response of bona fide memory $\mathrm{CD} 8^{+} \mathrm{T}$ cells if they encounter their cognate antigen.

A recent study suggested that under noninflamed conditions, memory $\mathrm{CD}^{+} \mathrm{T}$ cells do not possess a proliferative advantage, but may in fact have a higher antigenic threshold for cell-cycle entry than naive cells (8). Similarly, while the per-cell capacity for overall accumulation is greater for naive cells, systemic inflammation has a greater effect on the proliferative capacity of memory CD8 ${ }^{+}$ $\mathrm{T}$ cells (9). These studies suggested an important role for inflammatory cytokines in regulating the rapid proliferation of memory $\mathrm{CD}^{+} \mathrm{T}$ cells. Herein, we demonstrate that exposure to inflammatory cytokines prepares bona fide memory $\mathrm{CD} 8^{+} \mathrm{T}$ cells for rapid division independently of antigen reencounter. Our data clearly establish a key role for the type I IFN-dependent induction of IL-15 in regulating the cell-cycle entry of memory CD8 ${ }^{+} \mathrm{T}$ cells via the activation of the mTORC1-signaling pathway, leading to the activation of p70 S6 kinase. This, in turn, leads to an increase in the proliferative capacity of memory $\mathrm{CD} 8^{+} \mathrm{T}$ cells, resulting in heightened protection from chronic infection with LCMV clone 13 , a model in which the proliferation of memory $\mathrm{CD} 8^{+} \mathrm{T}$ cells is important for the control of viral load within the lymph nodes (37). Therefore, we demonstrate that the antigen-independent cell- 
cycle entry of memory $\mathrm{CD}^{+} \mathrm{T}$ cells following exposure to inflammatory cytokines represents more than a simple bystander effect. Instead, it prepares the whole memory $\mathrm{CD} 8^{+} \mathrm{T}$ cell population for rapid division upon cognate antigen encounter.

Together with previous work (11), our data define what we believe is a novel role for IL-15 in optimal responses to cognate antigen by memory $\mathrm{CD}^{+} \mathrm{T}$ cells. Previously, it was shown that exposure to inflammatory IL-15 regulated the de novo synthesis of core $2 \mathrm{O}$-glycans on memory $\mathrm{CD}^{+} \mathrm{T}$ cells to allow for the rapid trafficking of these cells to inflamed organs (11). In addition, we now demonstrate that exposure to IL-15 following viral infection leads to the cell-cycle entry of the majority of memory CD8 ${ }^{+} \mathrm{T}$ cells independently of antigenic encounter via activation of the mTOR pathway. Importantly, transient exposure to low concentrations of IL-15 is sufficient to increase the rate of proliferation of both mouse and human memory $\mathrm{CD}^{+} \mathrm{T}$ cells following TCR triggering. Furthermore, over the course of LCMV infection (when both cognate antigen and inflammatory cytokines are present), the proliferative rate of memory $\mathrm{CD}^{+} \mathrm{T}$ cells in the absence of IL-15 signaling was reduced compared with the same population of cells receiving IL-15-mediated signals. Thus, the proliferative advantage observed for memory $\mathrm{CD}^{+} \mathrm{T}$ cells is likely due in part to their heightened capacity to respond to inflammatory IL-15 and may be linked to their well-documented increased expression of CD122 (IL-2/IL15R $\beta$ ) compared with naive CD8 ${ }^{+} \mathrm{T}$ cells (38). This may be of particular interest when designing vaccine strategies that involve repeated boosting, as CD122 (IL-2/IL15R $\beta$ ) expression is reduced on memory $\mathrm{CD}^{+} \mathrm{T}$ cells following repeated antigenic stimulation (39). To this effect, multiply stimulated memory CD ${ }^{+}$ $\mathrm{T}$ cells have been demonstrated to exhibit poor recall responses and to be deficient in their protective capacity against chronic infection with LCMV clone 13 (37). This suggests that vaccination strategies leading to reduced CD122 (IL-2/IL15R $\beta$ ) expression may have detrimental consequences on the protective function of memory $\mathrm{CD}^{+} \mathrm{T}$ cells in response to at least some pathogens.

Thus, our data demonstrate another important role for inflammatory cytokines in the biology of memory $\mathrm{CD}^{+} \mathrm{T}$ cells. It is becoming increasingly clear that exposure to inflammatory cytokines prepares the whole memory $\mathrm{CD}^{+} \mathrm{T}$ cell population for optimal responses regardless of their antigenic specificity. This includes rapid migration to inflamed tissues $(10,11)$, regulation of $\mathrm{T}$ cell-intrinsic antigen sensitivity (12), and the capacity for rapid proliferation (as demonstrated in this study). This likely represents a set of important regulatory mechanisms that allow for optimal responses during infection while preventing the induction of immunopathology/autoimmunity at steady state. In support of this, both the proliferative capacity and the antigen sensitivity of memory CD8 ${ }^{+} \mathrm{T}$ cells are blunted in the absence of inflammatory stimuli $(8,12)$. Thus, sensing of inflammatory cytokines by memory $\mathrm{CD} 8^{+} \mathrm{T}$ cells serves as an early warning system resulting in a transient increase in the functionality of the whole population of memory $\mathrm{CD}^{+} \mathrm{T}$ cells, which returns to steady state unless cognate antigen is encountered. This may also play an important role in the capacity of memory $\mathrm{CD}^{+} \mathrm{T}$ cells to provide protection to some heterologous infection by increasing their capacity to rapidly respond to even weakly crossreactive antigens $(12,40,41)$. However, the role of inflammatory cytokines in heterologous immunity remains to be fully investigated. Conversely, the proper regulation of these mechanisms is likely to be critical to prevent crossreactive responses of memory $\mathrm{CD} 8^{+} \mathrm{T}$ cells to self antigens, and it will be of interest to determine whether some of these mechanisms are dysregulated in the development of autoimmunity.

In addition, our data clearly demonstrate that regulation of the cell-cycle entry of memory $\mathrm{CD} 8^{+} \mathrm{T}$ cells by inflammatory cytokines is more than a simple bystander effect. Rather, this represents an important component of the enhanced protective capacity of memory $\mathrm{CD}^{+} \mathrm{T}$ cells. Interestingly, different functions of memory $\mathrm{CD}^{+} \mathrm{T}$ cells are controlled by different cytokines, as we have previously demonstrated that type I IFN directly regulated the antigen sensitivity of $\mathrm{CD} 8^{+} \mathrm{T}$ cells (12) while it indirectly regulated the rapid proliferative capacity of memory $\mathrm{CD}^{+} \mathrm{T}$ cells through the induction of IL-15. In addition, other cytokines may be involved in regulating the proliferative capacity of memory CD8 ${ }^{+}$ $\mathrm{T}$ cells, as recent in vitro data have demonstrated a role for IL-12 and IL-18 in the induction of memory CD8 $8^{+} \mathrm{T}$ cell proliferation. The mechanism regulating proliferation of memory $\mathrm{CD} 8^{+} \mathrm{T}$ cells following IL-12/IL-18 stimulation in vitro was dependent on IL-2 production by $\mathrm{CD} 4^{+} \mathrm{T}$ cells (15). Our data, obtained with several experimental approaches, clearly demonstrate that, while IL-15 is involved in regulating memory $\mathrm{CD} 8^{+} \mathrm{T}$ cell proliferation over the course of viral infection in vivo, blocking IL-2 had no effect on the capacity of bystander viral infection to induce cell-cycle entry of memory CD8 ${ }^{+} \mathrm{T}$ cells. While the regulation of cell-cycle entry was entirely regulated by IL-15 following bystander infection with the viral model used in this study, it remains possible that other infections induce similar responses through mechanisms involving other cytokines (15). This suggests that specific inflammatory milieux induced over the course of different infections may regulate the proliferation of memory $\mathrm{CD}^{+} \mathrm{T}$ cells through different mechanisms. This concept warrants further investigation.

Furthermore, our data indicate a positive role for the mTOR pathway in the IL-15-driven proliferation of memory $\mathrm{CD} 8^{+} \mathrm{T}$ cells, which leads to enhanced antiviral protection. These data are in direct contrast to the currently accepted dogma that targeting the mTOR pathway with inhibitors such as rapamycin represents an effective strategy to improve memory $\mathrm{CD}^{+} \mathrm{T}$ cell responses (42). While inhibition of the mTOR pathway alters the course of $\mathrm{CD}^{+} \mathrm{T}$ cell differentiation, our data clearly demonstrate that inhibition of this pathway has a detrimental effect on the function of preexisting memory $\mathrm{CD}^{+} \mathrm{T}$ cell populations.

In conclusion, our data demonstrate that induction of inflammatory IL-15 following viral infection plays a critical role in the rapid proliferation and protective capacity of memory $\mathrm{CD}^{+} \mathrm{T}$ cells. Specifically, this allows memory $\mathrm{CD}^{+} \mathrm{T}$ cells to enter the cell cycle independently of antigen reencounter via the mTORC1 pathway. In turn, this primes memory $\mathrm{CD}^{+} \mathrm{T}$ cells for faster division upon antigenic encounter and is coupled with increased protective capacity from reinfection. Our data further highlight the importance of inflammatory cytokines in preparing memory CD8 ${ }^{+}$ $\mathrm{T}$ cells and the intricate interplay between inflammatory cytokines and antigenic stimulation resulting in optimal responses. This will likely have an impact on vaccine design approaches, as expression of specific cytokine receptors such as CD122 (IL-2/IL15R $\beta$ ) might be critical for optimal responses to specific infections. 


\section{Methods}

Mice and pathogens. C57BL/6 mice were purchased from the National Cancer Institute or bred at The University of Iowa. TCR Tg OT-I and P14 mice were previously described $(43,44)$. Ifnar/- mice were provided by M. Mescher (University of Minnesota, Minneapolis, Minnesota, USA), and Ifnar-- OT-I mice were generated by appropriate breeding. $I l 15^{-/}$mice were purchased from Taconic and bred at the University of Iowa. Infected mice were housed at the appropriate biosafety level. LCMV-ARM and clone 13 were propagated as described (45) and injected i.p. or i.v. $\left(2 \times 10^{5} \mathrm{PFU}\right.$ or $2 \times 10^{6} \mathrm{PFU}$, respectively). PV was propagated as described (46) and injected i.p. $\left(1 \times 10^{6} \mathrm{PFU}\right)$.

Human cells. Human $\mathrm{CD} 8^{+} \mathrm{T}$ cells were enriched from leukocyte reduction cones using a RosetteSep $\mathrm{CD}^{+} \mathrm{T}$ cells Enrichment Kit (StemCell Technologies) according to the manufacturer's instructions.

Antibodies and flow cytometry staining. The following antibodies were used in an appropriate combination of fluorochromes: CD8a (clone 53-6.7, BioLegend), CD11b (clone M1/70, eBioscience), CD11c (clone N418, eBioscience), CD19 (clone eBio1D3, eBioscience), CD44 (clone IM7, BioLegend), CD62L (clone MEL-14, eBioscience), CD215 (clone DNT15Ra, eBioscience), F4/80 (clone BMB, BioLegend), granzyme B (clone GB11, Life Technologies), IFN- $\gamma$ (clone XMG1.2, BioLegend), Ki-67 (clone B56, BD Bioscience), MHC class II (clone M5/114.15.2, BioLegend), Thy 1.1 (clone OX-7, eBioscience), Thy1.2 (clone 30H12, BioLegend), human CD8 $\alpha$ (clone HIT8a, BioLegend), human CD3 (clone HIT3a, BioLegend), human CD45RO (clone UCHL1, BioLegend), and appropriate isotype controls. Spleens and/ or lymph nodes were isolated and mechanically disrupted to generate single-cell suspensions. Erythrocytes were lysed with ACK buffer, cells were stained with the indicated antibodies, and samples were fixed using BD Cytofix/Cytoperm. Intracellular staining for Ki-67 was performed using the FoxP3 staining buffer set (eBioscience) according to the manufacturer's instructions. Samples were analyzed with a BD LSRFortessa flow cytometer (BD Biosciences) and FlowJo software (Tree Star).

Generation of memory cells and adoptive transfers. For generation of primary memory cells, naive Thy1.1 OT-I $\left(1 \times 10^{3}\right)$ or P14 CD8 ${ }^{+} \mathrm{T}$ cells $\left(1-5 \times 10^{4}\right)$ were injected i.v. into naive Thy1.2 WT recipients that were infected with either $\mathrm{Acta}^{-/-} \mathrm{LM}$-OVA $\left(5 \times 10^{6} \mathrm{CFU}\right)$ or LCMVARM $\left(2 \times 10^{5} \mathrm{PFU}\right)$, respectively. Mice were rested at least 50 days before use. Where indicated, naive or memory $\mathrm{CD} 8^{+} \mathrm{Tg} \mathrm{T}$ cells were enriched following standard autoMACS purification protocols and transferred $\left(2 \times 10^{6}\right)$ into congenic naive recipients. Where indicated, enriched memory or naive CD $8^{+} \mathrm{T}$ cells were labeled with $1 \mu \mathrm{M}$ CFSE or $2 \mu \mathrm{M}$ CTV (Life Technologies) prior to transfer.

Microarray analysis. Memory P14 cells were flow sorted on day 4 following mock infection with saline or infection with PV with or without daily i.p. injection of anti-CD122 (clone TM- $\beta 1,200 \mu$ g, i.p., BioXCell). At least $1 \times 10^{6}$ memory P14 cells were sorted per pool. RNA was extracted from 3 independent pools of memory P14 cells from all groups using an RNeasy kit (QIAGEN) according to the manufacturer's instructions. Microarray analysis was performed at the DNA Core facility at the University of Iowa. RNA quality was assessed using the Agilent Model 2100 Bioanalyzer along with the NanoDrop ND-1000. Fifty nanograms total RNA was converted to SPIA-amplified cDNA using the WT-Ovation Pico RNA Amplification System, v2 (NuGEN Technologies), according to the manufacturer's instructions. Samples were hybridized onto Affymetrix Mouse Exon 1.0 ST arrays and scanned with the Affymetrix Model 3000 scanner with 7G upgrade. Data were collected using GeneChip operating software (GCOS) v1.4. Data were imported into Partek GS v. 6.12. Normalized $\log _{2}$ data were compared using an ANOVA model. Individual comparisons were done using a linear model function. Genes with a $P$ value less than 0.01 and a fold-change greater than 1.5 were analyzed further. DAVID analysis was performed as previously described $(23,24)$. All original microarray data were deposited in the NCBI's Gene Expression Omnibus (GEO GSE69791).

Blocking antibody and rapamycin treatments. Where indicated, mice were treated with daily injections of anti-CD122 (clone TM- $\beta 1$,

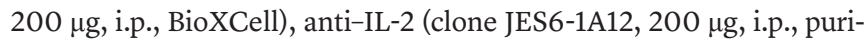
fied from hybridomas purchased from ATCC; ref. 47), or rat IgG control (200 $\mu$ g, i.p., Sigma-Aldrich). Where indicated, mice were treated with daily injections of rapamycin (1.5 mg/kg, i.p., Calbiochem).

ELISA. IL-15 protein was quantified with a mouse IL-15R/IL-15 Complex ELISA Ready-SET-Go Kit from eBioscience according to the manufacturer's instructions. Spleens were harvested on day 2 following infection and homogenized in $1 \mathrm{ml} \mathrm{RIPA}$ buffer $(50 \mathrm{mM}$ Tris [pH 7.4], 1\% NP-40, 0.1\% SDS, $150 \mathrm{mM} \mathrm{NaCl,} \mathrm{0.5 \%} \mathrm{sodium} \mathrm{deoxy-}$ cholate, $1 \mathrm{mM}$ EDTA, and protease inhibitors).

RNA isolation and quantitative RT-PCR analysis. RNA was isolated from total spleens on day 2 following infection with PV or mock infection using an RNeasy kit (QIAGEN) according to the manufacturer's instructions. Quantitative real-time-PCR (RT-PCR) was performed using an iTaq Universal SYBR Green One-Step Kit (Bio-Rad), and data were acquired using the Applied Biosystems Model 7900HT real-time PCR system. Fold-changes were calculated using the $\Delta \Delta \mathrm{Ct}$ method normalizing to tata-binding protein (TBP) expression. Primers used were as follows: Il15 sense: 5'-CATATGGAATCCAACTGGATAGATGTAAGATA-3'; Il15 anti-sense: 5'-CATATGCTCGAG GGACGTGTTGATGAACAT-3'; Tbp sense: 5'-TGGAATTGTACCGCAGCTTCA-3'; Tbp antisense: 5'-ACTGCAGCAAATCGCTTGGG-3' (Integrated DNA Technologies).

In vitro stimulation. Memory P14 cells were enriched as described above, labeled with CTV, and cultured in FCS-supplemented RPMI for 4 days. Recombinant murine IL-15 (0.5-1 ng/ml; Peprotech) was added to cultures daily. On day 4, cells were washed to remove IL-15 and were stimulated with $0.5 \mu \mathrm{M}$ of $\mathrm{gp}_{33-41}$ peptide and analyzed daily by flow cytometry for cell division based on CTV dilution (memory P14 cells were gated based on CD8 $\alpha$ and Thy1.1 expression). Human $\mathrm{CD}^{+} \mathrm{T}$ cells were enriched as described above, labeled with CTV, and cultured as described above. Recombinant human IL-15 (0.5-2 ng/ml; Peprotech) was added to cultures daily. On day 4, cells were washed to remove IL-15 and stimulated with $0.5 \mu \mathrm{g} / \mathrm{ml}$ of plate-bound anti-CD3 antibody (clone OKT3, eBioscience) and analyzed daily for cell division based on CTV dilution (antigen-experienced $\mathrm{CD}^{+} \mathrm{T}$ cells were gated based on $\mathrm{CD} 8 \alpha, \mathrm{CD} 3$, and CD45RO expression).

IL-15 stimulation and immunoblot analysis. Memory P14 CD8 ${ }^{+} \mathrm{T}$ cells were generated as described above and enriched following standard autoMACS purification protocols. From 5 to $10 \times 10^{6}$ cells were either left untreated or stimulated with $250 \mathrm{ng} / \mathrm{ml}$ murine IL-15 (Peprotech) alone or in the presence of either $100 \mu \mathrm{M}$ of STAT5 inhibitor ( $N^{\prime}$-[(4-oxo-4H-chromen-3-yl)methylene]nicotinohydrazide, Calbiochem) or $200 \mathrm{nM}$ rapamycin (Calbiochem) for 30 minutes at $37^{\circ} \mathrm{C}$. Cells were washed in ice-cold PBS and lysed in NP-40 buffer $(20 \mathrm{mM}$ HEPES [pH 7.9], $100 \mathrm{mM} \mathrm{NaCl}, 5 \mathrm{mM}$ EDTA, $0.5 \mathrm{mM} \mathrm{CaCl}_{2}$, $1 \%$ Non- 
idet P-40, $1 \mathrm{mM}$ PMSF, $10 \mu \mathrm{g} / \mathrm{ml}$ leupeptin, $10 \mu \mathrm{g} / \mathrm{ml}$ pepstatin, $1 \mathrm{mM}$ $\left.\mathrm{Na}_{3} \mathrm{VO}_{4}\right)$. Protein $(10 \mu \mathrm{g})$ was resolved by SDS-PAGE transferred to PVDF membranes and probed with the indicated antibodies (phosphop70 S6 kinase [Thr389, clone 108D2] rabbit mAb and p70 S6 kinase [clone 49D7] rabbit mAb, Cell Signaling). Antibodies were detected with HRP-conjugated goat anti-rabbit secondary antibodies (Santa Cruz Biotechnology Inc.) and WestPico Supersignal chemiluminescent substrate (Thermo Scientific).

Ex vivo cytokine analysis. Ex vivo cytokine analysis was performed as previously described (12). Briefly, splenocytes were incubated for 5 hours with the indicated concentrations of stimulating peptide in the presence of Brefeldin A (BioLegend). Cells were subsequently surface stained for the appropriate markers, permeabilized, and stained for the cytokine of interest and analyzed by flow cytometry.

Analysis of viral burden. Memory P14 cells were enriched as described and adoptively transferred $\left(2 \times 10^{6}\right.$ cells/mouse $)$ as indicated. Mice were infected 1 day later with LCMV clone $13\left(2 \times 10^{6}\right.$ $\mathrm{PFU}$, i.v.). Mice were treated with daily injections of either anti-CD122 (TM- $\beta 1,200 \mu$ g, i.p., BioXCell) or rat IgG control (200 $\mu$ g, i.p., SigmaAldrich). On day 3 after infection, inguinal lymph nodes were homogenized and viral titers were measured by standard plaque assay procedures as previously described (37).

Statistics. Data were analyzed with GraphPad Prism 4 software. Specific tests (either 2-tailed unpaired Student's $t$ test or 1-way ANOVA with Tukey's post-test of multiple comparisons) for determining statistical significance are indicated in the figure legends. $P<0.05$ was considered significant.

Study approval. The University of Iowa Animal Care and Use Committee approved all animal experiments. Human blood leukocytes were acquired from anonymous donors from the DeGowin Blood Center at
The University of Iowa who had consented for blood donation. The University of Iowa's Institutional Review Board approved all consent forms.

\section{Acknowledgments}

We thank members of the Harty Lab, S. Condotta, J. Nolz, and S. Perlman for comments and discussion. We also thank the University of Iowa DNA core, Division of Bioinformatics and Flow Cytometry Facility. The Flow Cytometry Facility is funded through user fees and the generous financial support of the Carver College of Medicine, the Holden Comprehensive Cancer Center, and the Iowa City Veteran's Administration Medical Center. The flow cytometry core is supported by NCI and NIH grants (P30CA086862 and 1S10 RR027219). M.J. Richer was supported by a Canadian Institutes of Health research fellowship and a fellowship from the American Heart Association Midwest Affiliate. The J.T. Harty lab is supported by NIH grants (AI42767, AI085515, AI95178, AI100527, AI106776).

Address correspondence to: John T. Harty, University of Iowa, Department of Microbiology, 3-512 Bowen Science Building, 51 Newton Rd., Iowa City, Iowa 52242, USA. Phone: 319.335.9720; E-mail: john-harty@uiowa.edu. Or to: Martin J. Richer, McGill University, Department of Microbiology and Immunology, Microbiome and Disease Tolerance Centre, 406A Duff Medical Building, 3775 University Street, Montreal, Quebec, Canada, H3A 2B4. Phone: 514.398.4400, ext. 00538; E-mail: martin.j.richer@mcgill.ca.

Martin J. Richer's present address is: Department of Microbiology and Immunology, Microbiome and Disease Tolerance Centre, McGill University, Montreal, Quebec, Canada.
1. Cho BK, Wang C, Sugawa S, Eisen HN, Chen J. Functional differences between memory and naive CD8 T cells. Proc Natl Acad Sci US A. 1999;96(6):2976-2981.

2. Barber DL, Wherry EJ, Ahmed R. Cutting edge: rapid in vivo killing by memory CD8 T cells. Jimmunol. 2003;171(1):27-31.

3. Whitmire JK, Eam B, Whitton JL. Tentative T cells: memory cells are quick to respond, but slow to divide. PLoS Pathog. 2008;4(4):e1000041.

4. Veiga-Fernandes H, Walter U, Bourgeois C, McLean A, Rocha B. Response of naive and memory $\mathrm{CD}^{+} \mathrm{T}$ cells to antigen stimulation in vivo. Nat Immunol. 2000;1(1):47-53.

5. Veiga-Fernandes H, Rocha B. High expression of active CDK6 in the cytoplasm of CD8 memory cells favors rapid division. Nat Immunol. 2004;5(1):31-37.

6. Zimmermann C, Prevost-Blondel A, Blaser C, Pircher $\mathrm{H}$. Kinetics of the response of naive and memory CD8 T cells to antigen: similarities and differences. Eur J Immunol. 1999;29(1):284-290.

7. Allam A, et al. The CD8 ${ }^{+}$memory T-cell state of readiness is actively maintained and reversible. Blood. 2009;114(10):2121-2130.

8. Mehlhop-Williams ER, Bevan MJ. Memory $\mathrm{CD}^{+} \mathrm{T}$ cells exhibit increased antigen threshold requirements for recall proliferation. J Exp Med. 2014;211(2):345-356.

9. Martin MD, Condotta SA, Harty JT, Badovinac
VP. Population dynamics of naive and memory CD8 T cell responses after antigen stimulations in vivo. J Immunol. 2012;188(3):1255-1265.

10. Ely KH, Cauley LS, Roberts AD, Brennan JW, Cookenham T, Woodland DL. Nonspecific recruitment of memory $\mathrm{CD} 8^{+} \mathrm{T}$ cells to the lung airways during respiratory virus infections. J Immunol. 2003;170(3):1423-1429.

11. Nolz JC, Harty JT. IL-15 regulates memory CD8 ${ }^{+}$ T cell O-glycan synthesis and affects trafficking. J Clin Invest. 2014;124(3):1013-1026.

12. Richer MJ, Nolz JC, Harty JT. Pathogen-specific inflammatory milieux tune the antigen sensitivity of CD8(+) T cells by enhancing T cell receptor signaling. Immunity. 2013;38(1):140-152.

13. Kim SK, Brehm MA, Welsh RM, Selin LK. Dynamics of memory $\mathrm{T}$ cell proliferation under conditions of heterologous immunity and bystander stimulation. J Immunol. 2002;169(1):90-98.

14. Masopust D, Murali-Krishna K, Ahmed R. Quantitating the magnitude of the lymphocytic choriomeningitis virus-specific CD8 T-cell response: it is even bigger than we thought. J Virol. 2007;81(4):2002-2011.

15. Raue HP, Beadling C, Haun J, Slifka MK. Cytokine-mediated programmed proliferation of virus-specific CD8(+) memory T cells. Immunity. 2013;38(1):131-139.

16. Tough DF, Borrow P, Sprent J. Induc- tion of bystander $\mathrm{T}$ cell proliferation by viruses and type I interferon in vivo. Science. 1996;272(5270):1947-1950.

17. Zhang X, Sun S, Hwang I, Tough DF, Sprent J. Potent and selective stimulation of memoryphenotype CD8 ${ }^{+} \mathrm{T}$ cells in vivo by IL-15. Immunity. 1998;8(5):591-599.

18. Schluns KS, Williams K, Ma A, Zheng XX, Lefrancois L. Cutting edge: requirement for IL-15 in the generation of primary and memory antigen-specific CD8 T cells. J Immunol. 2002;168(10):4827-4831.

19. Becker TC, et al. Interleukin 15 is required for proliferative renewal of virus-specific memory CD8 T cells. J Exp Med. 2002;195(12):1541-1548.

20. Goldrath AW, et al. Cytokine requirements for acute and Basal homeostatic proliferation of naive and memory $\mathrm{CD}^{+} \mathrm{T}$ cells. J Exp Med. 2002;195(12):1515-1522.

21. Ku CC, Murakami M, Sakamoto A, Kappler J, Marrack P. Control of homeostasis of CD8 ${ }^{+}$ memory T cells by opposing cytokines. Science. 2000;288(5466):675-678.

22. Mogensen TH, Paludan SR. Molecular pathways in virus-induced cytokine production. Microbiol Mol Biol Rev. 2001;65(1):131-150.

23. Huang DW, Sherman BT, Lempicki RA. Systematic and integrative analysis of large gene lists using DAVID bioinformatics resources. Nat Protoc. 2009;4(1):44-57. 
24. Huang DW, Sherman BT, Lempicki RA. Bioinformatics enrichment tools: paths toward the comprehensive functional analysis of large gene lists. Nucleic Acids Res. 2009;37(1):1-13.

25. Scholzen T, Gerdes J. The Ki-67 protein: from the known and the unknown. JCell Physiol. 2000;182(3):311-322.

26. Biron CA. Initial and innate responses to viral infections - pattern setting in immunity or disease. Curr Opin Microbiol. 1999;2(4):374-381.

27. Nguyen KB, et al. Coordinated and distinct roles for IFN- $\alpha \beta$, IL-12, and IL-15 regulation of NK cell responses to viral infection. J Immunol. 2002;169(8):4279-4287.

28. Mattei F, Schiavoni G, Belardelli F, Tough DF. IL-15 is expressed by dendritic cells in response to type I IFN, double-stranded RNA, or lipopolysaccharide and promotes dendritic cell activation. J Immunol. 2001;167(3):1179-1187.

29. Waldmann TA. The biology of interleukin-2 and interleukin-15: implications for cancer therapy and vaccine design. Nat Rev Immunol. 2006;6(8):595-601.

30. Waickman AT, Powell JD. mTOR, metabolism, and the regulation of T-cell differentiation and function. Immunol Rev. 2012;249(1):43-58.

31. Song J, Salek-Ardakani S, So T, Croft M. The kinases aurora $\mathrm{B}$ and $\mathrm{mTOR}$ regulate the G1-S cell cycle progression of T lymphocytes. Nat Immunol. 2007;8(1):64-73.

32. Marcais A, et al. The metabolic checkpoint kinase
mTOR is essential for IL-15 signaling during the development and activation of NK cells. Nat Immunol. 2014;15(8):749-757.

33. Laplante M, Sabatini DM. mTOR signaling in growth control and disease. Cell. 2012;149(2):274-293.

34. Kohlmeier JE, Cookenham T, Roberts AD, Miller SC, Woodland DL. Type I interferons regulate cytolytic activity of memory CD8(+) T cells in the lung airways during respiratory virus challenge. Immunity. 2010;33(1):96-105.

35. Kim DH, et al. mTOR interacts with raptor to form a nutrient-sensitive complex that signals to the cell growth machinery. Cell. 2002;110(2):163-175.

36. Fingar DC, Richardson CJ, Tee AR, Cheatham L, Tsou C, Blenis J. mTOR controls cell cycle progression through its cell growth effectors S6K1 and $4 \mathrm{E}-\mathrm{BP} 1 /$ eukaryotic translation initiation factor 4E. Mol Cell Biol. 2004;24(1):200-216.

37. Nolz JC, Harty JT. Protective capacity of memory $\mathrm{CD} 8^{+} \mathrm{T}$ cells is dictated by antigen exposure history and nature of the infection. Immunity. 2011;34(5):781-793.

38. Boyman O, Sprent J. The role of interleukin-2 during homeostasis and activation of the immune system. Nat Rev Immunol. 2012;12(3):180-190.

39. Wirth TC, et al. Repetitive antigen stimulation induces stepwise transcriptome diversification but preserves a core signature of memory CD8(+) T cell differentiation. Immunity. 2010;33(1):128-140.
40. Selin LK, Varga SM, Wong IC, Welsh RM. Protective heterologous antiviral immunity and enhanced immunopathogenesis mediated by memory T cell populations. J Exp Med. 1998;188(9):1705-1715.

41. Welsh RM, Che JW, Brehm MA, Selin LK. Heterologous immunity between viruses. Immunol Rev. 2010;235(1):244-266.

42. Araki K, et al. mTOR regulates memory CD8 T-cell differentiation. Nature. 2009;460(7251):108-112.

43. Hogquist KA, Jameson SC, Heath WR, Howard JL, Bevan MJ, Carbone FR. T cell receptor antagonist peptides induce positive selection. Cell. 1994;76(1):17-27.

44. Pircher $\mathrm{H}$, et al. Characterization of virus-specific cytotoxic $\mathrm{T}$ cell clones from allogeneic bone marrow chimeras. Eur J Immunol. 1987;17(2):159-166.

45. Slifka MK, Whitton JL. Functional avidity maturation of $\mathrm{CD} 8(+) \mathrm{T}$ cells without selection of higher affinity TCR. Nat Immunol. 2001;2(8):711-717.

46. Varga SM, Selin LK, Welsh RM. Independent regulation of lymphocytic choriomeningitis virusspecific $\mathrm{T}$ cell memory pools: relative stability of CD4 memory under conditions of CD8 memory T cell loss. JImmunol. 2001;166(3):1554-1561.

47. Starbeck-Miller GR, Xue HH, Harty JT. IL-12 and type I interferon prolong the division of activated CD8 T cells by maintaining high-affinity IL-2 signaling in vivo. J Exp Med. 2014;211(1):105-120. 